\title{
Enriched Background Isotope Study (EBIS)
}

FINAL PROJECT REPORT

DOE's Office of Science, Biological and Environmental Research (BER),

Terrestrial Carbon Processes (TCP) Program

Submitted by the EBIS Working Group

March 3, 2006 (Revised March 12, 2006)

Paul J. Hanson1, Susan Trumbore2, Chris Swanston3, Margaret Torn4, Julie Jastrow5,

William A. Parton6, Wilfred M. Post1, Mats J. Fröberg1, Laura J. Hainsworth3, Markus Kleber4,

Christiane Kramer2, Roser Matamala-Paradedas and Charles T. Garten Jr.1

1ORNL = Oak Ridge National Laboratory, Oak Ridge, TN 37831

2UC-Irvine = University of California, Irvine, CA 92697

3LLNL-CAMS = Lawrence Livermore National Laboratory, Livermore, CA 94550

4LBNL = Lawrence Berkeley National Laboratory, Berkeley, CA, 97420

$5 \mathrm{ANL}=$ Argonne National Laboratory, Argonne, IL 60439

${ }_{6} \mathrm{CSU}=$ Colorado State University/Century Ecosystems, Inc.

EBIS Project Web Site:

http://ebis.ornl.gov/ 
TABLE OF CONTENTS

Project Summary and Workshop Highlights

Key scientific findings

Operational progress

Post-workshop deliverables for FY2006

EBIS Background and Approach

Progress to Date

A. EBIS manipulation study results

$\begin{array}{ll}\text { Experimental litter manipulations } & 10\end{array}$

$\begin{array}{ll}{ }^{14} \mathrm{C} \text { analyses } & 10\end{array}$

Bulk ${ }^{14} \mathrm{C}$-signatures: annual assessments 11

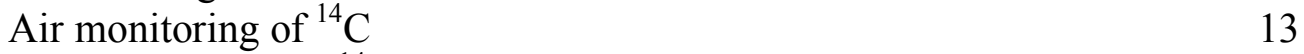

$\begin{array}{ll}\text { Temporal trends of }{ }^{14} \mathrm{C} \text { in plant tissues } & 14\end{array}$

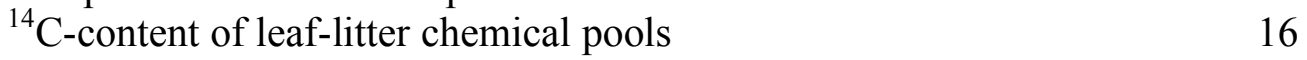

Forms and fate of carbon in soils

Aggregate-based $\quad 17$

$\begin{array}{ll}\text { Density-based } & 20\end{array}$

Observations on soil mineralogy $\quad 21$

Microbial biomass ${ }^{14} \mathrm{C} \quad 22$

Tracer ${ }^{15} \mathrm{~N}$ and natural abundance ${ }^{13} \mathrm{C}$ studies $\quad 23$

$\begin{array}{ll}\text { Site vegetation and litter production } & 24\end{array}$

B. New Initiatives

Mesocosm study of litter to A-horizon DOC transport 26

Root turnover and decomposition $\quad 27$

Compound-specific radiocarbon values on phospholipid fatty acids 29

C. Integration: Modeling and Mass Balance

Enriched Litter Cohort model - ECHO 31

Root modeling - Radix $\quad 34$

$\begin{array}{ll}\text { Daycent modeling } & 37\end{array}$

RothC modeling $\quad 41$

$\begin{array}{ll}\text { DyDOC modeling } & 42\end{array}$

Soil C and ${ }^{14} \mathrm{C}$ Mass Balance $\quad 43$

List of Publications and Presentations 45

$\begin{array}{ll}\text { List of Workshop Participants } & 49\end{array}$ 


\section{PROJECT SUMMARY AND WORKSHOP HIGHLIGHTS}

Elevated levels of ${ }^{14} \mathrm{C}$ enriched $\mathrm{CO}_{2}$ in the air and soil atmosphere as well as leaf, stem, and root tissues were observed on the Oak Ridge Reservation (ORR) during the summer of 1999, and were attributed to local incinerator activities on and/or near the ORR. The isolated enrichment of ${ }^{14} \mathrm{C}$ in local forest ecosystems represented a unique opportunity to study unresolved carbon cycling processes such as the contribution of leaf versus root litter to soil carbon accumulation, the rate of vertical transport of carbon into deep soil storage pools, and the differential contribution of physicochemical versus faunal driven processes to soil carbon cycling and sequestration. We are conducting a cooperative, multi-institutional study, centered on a field manipulation experiment, which takes advantage of the whole-ecosystem isotopic label generated by the $1999{ }^{14} \mathrm{C}$-release. Experimental results from this study are being used to parameterize and refine existing carbon dynamics models for the quantification of the long-term fate of ecosystem carbon inputs and the potential for ecosystem carbon sequestration.

In 2004 and again in 2005, new atmospheric pulses of ${ }^{14} \mathrm{CO}_{2}$ led to biological enrichment of the western sites and entire Oak Ridge Reservation, respectively. These pulses bring a logical end to the initial field-scale manipulation study, but provide an opportunity for us to calibrate the size of the initial 1999 exposure and to conduct rigorous tests of the EIBS-improved models of leaf and root litter soil $\mathrm{C}$ inputs that we have developed. This report summarizes experimental progress by all participants from 2001 to 2005. The following bullets provide highlights from the workshop derived from the task-specific progress descriptions provided in this report.

\section{Key Scientific Findings to Date:}

- Initial EBIS observations from all experimental tasks supported the conclusion that intra- and interannual soil carbon cycling in eastern deciduous hardwood forest soils should be characterized as a two-compartment system with surface litter inputs representing the primary carbon source for an organic-layer carbon cycle, and root litter inputs the primary carbon source for a mineral-soil carbon cycle. After 3-years of litter manipulation and 4 years of tracking wet are beginning to see the signature of enriched, litter-addition carbon appearing within the A horizon of the mineral soils.

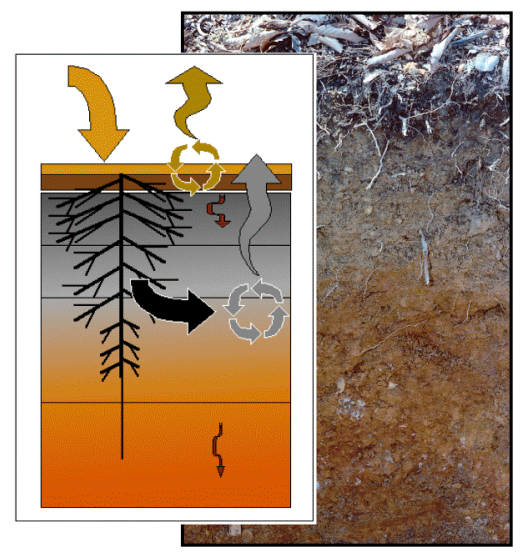

- Analyses of ${ }^{14} \mathrm{C}$-signatures of bulk organic horizons have begun to indicate the arrival of enriched litter into the humus $(\mathrm{Oe} / \mathrm{Oa})$ layer 4-years after the initiation of litter manipulations. This step-by-step downward migration of litter cohorts over time is consistent with a humus layer turnover time on the order of $\sim 9$ years similar to values suggest by bomb- ${ }^{14} \mathrm{C}$ analysis at Walker Branch.

- Dissolved-organic-carbon (DOC) measurements from subsurface lysimeters show evidence of rapid movement of ${ }^{14} \mathrm{C}$-labeled-litter-C into deep soils, but the quantity of carbon moved by DOC transport into deep soils is small $\left(<10 \mathrm{gC} \mathrm{m}^{-2} \mathrm{y}^{-1}\right)$. Carbon 
accumulation associated with soil Fe-oxide content in Ultisols at depth has been demonstrated as a viable mechanism for $\mathrm{C}$ immobilization, but EBIS observations suggest the annual net rate of such accumulation would be small.

- Multiple-cohort organic-layer models with realistic

representations of the shortterm dynamics of decomposition and DOC leaching do explain observed patterns of $\Delta \Delta^{14} \mathrm{C}$. Such models will be needed to successfully

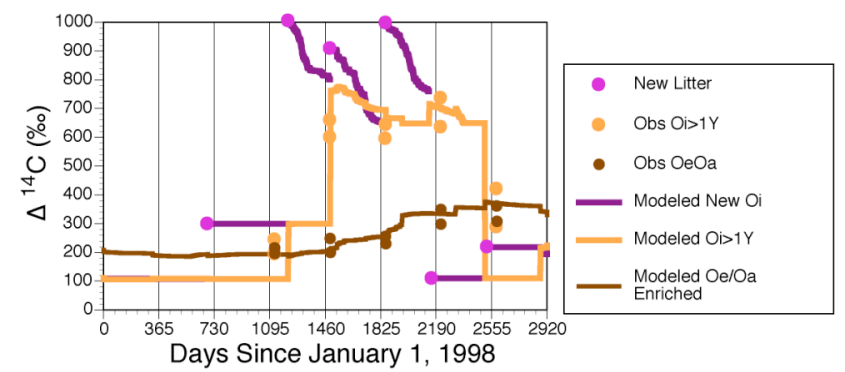
capture organic layer $\mathrm{C}$ cycling and $\mathrm{C}$ transfer to the mineral soil.

- The EBIS experimental design has allowed the use of combinations of enriched radiocarbon litter and soils to partition soil respiration among three components: autotrophic (root) respiration, leaf litter decomposition, and decomposition of dead roots and other organic matter substrates. Leaf litter decomposition (derived from the difference between elevated and background plots) contributes $\sim 10-40 \%$ of the total soil respiration flux, with variations tied to leaf litter moisture conditions and season. Root respiration contributes $40-80 \%$ of total soil respiration, with highest relative contributions before leaf-out and after senescence. Overall, variability in total soil respiration flux is more closely linked to differences in heterotrophic respiration sources than to autotrophic sources. Specifically, increased respiration immediately following a rainfall event during summer drought can be explained entirely through decomposition of $<3$ year old leaf litter; subsequent re-wetting (i.e. of already wet litter) made little difference in the sources of soil-respired C.

- Observation of the $\Delta^{14} \mathrm{C}$ signatures of root tissues over time has provided considerable insight into root turnover processes. These measurements are unique in the history of research on the processes of fine root production, mortality, and decomposition. Measured changes in root $\Delta^{14} \mathrm{C}$ were used to develop a root turnover model that accounts for all transfers of ${ }^{14} \mathrm{C}$ over time. There is evidence that in the surface horizons the very fine roots $(<0.5 \mathrm{~mm})$ turn over slightly more rapidly than the medium fine roots $(0.5$ to $2.0 \mathrm{~mm}$ ), but support for this size class difference appears to decline with depth.

- The ${ }^{14} \mathrm{C}$-signature of root respiration indicates that the $\mathrm{C}$ respired is derived both from (1) fresh (last few days to weeks) photosynthetic products and (2) nonstructural carbohydrate pools that have turnover times of a year or more. An isotope mass balance shows that the fraction of root respiration derived from NSC (starch and soluble sugar) pools decreases from $\sim 70 \%$ prior to leaf-out to $<40 \%$ in August-September.

- Fractionation of soil $\mathrm{C}$ by particle size and secondary organization into microaggregates supports our original hypothesis that relatively greater proportions of labeled root inputs 
will be physically protected by incorporation into microaggregates. Enriched $\operatorname{root} \mathrm{C}$ is steadily accumulating in microaggregated silt- and clay-sized particles in addition to microaggregated particulate organic matter. In non-microaggregated soil, however, the level of enrichment in silt- and clay-sized particles has changed little since the experiment started. This 'aggregate-based' fractionation approach provides the sensitivity needed to observe increasing ${ }^{14} \mathrm{C}$-signatures of several fractions from the multi-year enriched litter treatment. Differences between soil types in the fractions that are being enriched are hypothesized to be related to differences in sites available for sorption of dissolved organic C within specific soils (Ultisols vs. Inceptisols).

- Density-based methods for isolating functionally different soil organic matter pools have successfully traced enriched ${ }^{14} \mathrm{C}$ from litter and roots into unprotected, protected, and mineral-associated pools. The Ultisol sites, initially dominated by root inputs, showed no appreciable contribution from surface litter. Inceptisol mineral soils also receive the majority of their $\mathrm{C}$ inputs from root inputs, but appear to incorporate enriched litter ${ }^{14} \mathrm{C}$. Both soil types reveal a general path of rapid particulate input into the unprotected particulate pool (free light fraction), followed by a much slower incorporation from the free light fraction into the protected particulate pool (occluded light fraction). The Ultisols more effectively stabilize non-particulate SOM, but the mineral fractions of both soil types clearly include a fastand slow-cycling pool.

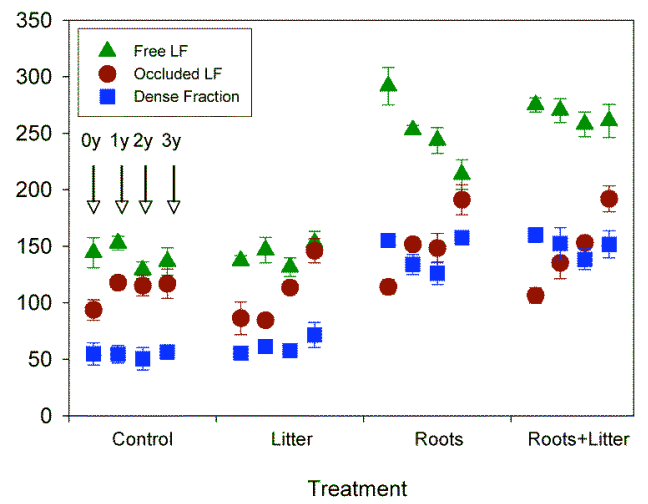

- A generic carbon cycling model based on fixed turnover-time assumptions for litter and soil $\mathrm{C}$ pools (i.e., Roth-C) did not adequately capturing the dynamics of organic layer $\mathrm{C}$ cycling indicated by the measured changes in ${ }^{14} \mathrm{C}$. Modifications to Roth-C and the Daycent model to include independent organic-layer carbon pools have been constructed to better align model predictions of $\mathrm{C}$ pool structure, decomposition dynamics, and isotopic composition with field observations. A model of root growth, senescence, and turnover (Radix) was developed and tested with ${ }^{14} \mathrm{C}$ observations from the first 3 years of EBIS. By creating two distinct pools of live roots (with turnover times on order of months and $>5 \mathrm{y}$ ), the model was able to explain the relatively rapid enrichment of live roots only one year after the release (caused by turnover of the short-lived roots), and the relatively slow decline of the enrichment in the subsequent years (caused by persistence of the long-lived roots). To capture the complexity of root dynamics while keeping the number of unknowns tractable, the model was designed with: root ages that are nonnormally distributed; fine roots pools, with both structural and non-structural C; seasonal patterns of growth and respiration; Monte Carlo analysis of uncertainty, and $\mathrm{aX}^{2}$ approach to find best-fit parameters to match root $\mathrm{C}$ and $\Delta^{14} \mathrm{C}$ data. In the past year, the 
model has been used to analyze the use of stored $\mathrm{C}$ reserves by trees for the growth of new roots. Manuscripts are in preparation for submittal in FY2006 that document the model and the analysis of growth from stored carbon.

- Evaluation of the $\mathrm{C}$ mass balance for the bulk forest soils provides a reasonable accounting of $\mathrm{C}$ sources, sinks and losses, but a key uncertainties remains associated with the rate of root litter production. Organic- to mineral-layer vertical transfers of particulate and dissolved organic carbon also still need to be resolved to explain $\mathrm{C}$ mass balance for the Oe/Oa (humus layer) and A horizons of the soil.

- New mid-season pulses of ${ }^{14} \mathrm{C}$ observed in the summer of 2004 were of sufficient magnitude to increase the ${ }^{14} \mathrm{C}$ signature of new root growth at western EBIS sites (TVA and Pine Ridge). Stronger pulses in 2005 impacted the entire reservation. These pulses represents a opportunity calibrate the size of the initial 1999 pulse and conduct new evaluations of root turnover and decomposition that were

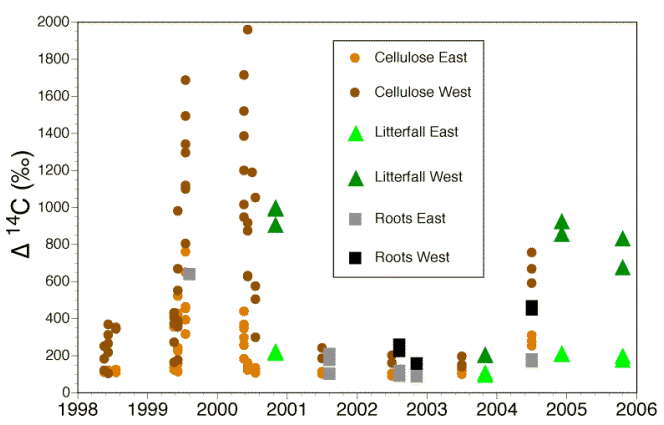
missed in 1999.

- Completed Ph.D. -- Malu Cisneros-Dozal, University of California at Irvine.

- Prof. Edward Tipping of the Center for Ecology and Hydrology, Lancaster in collaboration with Dr Paul Chamberlain have obtained independent research funding from The United Kingdom Natural Environment Research Council to fund a project titled "Modelling DOC production, transport and retention in forest soils, exploiting recent ${ }^{14} \mathrm{C}$ enrichment at Oak Ridge, USA."

\section{Operational-progress to date:}

- All cohorts of enriched or background litter were added to the EBIS treatment plots in 2001, 2002, and 2003 representing three full years of litter manipulations, and three additional years of ambient litter have followed. This sequence of distinct ${ }^{14} \mathrm{C}$ litter inputs provides a strong record of litter cohort additions from which to test the efficacy of a range of $\mathrm{C}$ cycling models.

- Vegetation cover, litter production, species composition, and climate were found to be comparable across the four spatially distributed EBIS research sites and will allow similar analysis of carbon cycling processes and mass balance for site-to-site comparisons.

- The Center for Accelerator Mass Spectrometry at Lawrence Livermore National Laboratory processed more than $5000{ }^{14} \mathrm{C}$-samples in support of the EBIS research project during the first 3-years of the EBIS study.

- A subcontract between ORNL and Bill Parton was initiated in 2005 to apply the Daycent model to the EBIS data, and contrast it with RothC improvements already underway. 
- New atmospheric releases of ${ }^{14} \mathrm{C}$ have taken place since the large pulse in 1999. However, measured releases in 2000, 2002, and 2003 did not overlap with the growing season and are of no concern to the interpretation of the main EBIS study through the 2004 annual sampling.

- A mesocosm study was initiated to evaluate the initial intra-annual transport of leaf litter $\mathrm{C}$ from fresh litter to the humus layer and A-horizon soils. This study is critical to capturing a key pathway of organic to mineral soil C transport that was not resolved by the plot-scale EBIS manipulations.

- PDF versions of the power point presentations given at the Gaithersburg (2004), Livermore (2005), and Argonne (2006) workshops are or will be available for downloading at http://ebis.ornl.gov.

Post-workshop deliverables for 2006 and 2007:

1. Posting of Argonne workshop presentations on the project web site - Completed.

2. Submission of the Argonne EBIS workshop report to DOE - This report.

3. Prepare proposals for the TCP solicitation for (a) FY2007 funding for adequate closure of the EBIS project and mesocosm study, and (b) a new 'EBIS-like' initiative on the organic-to-mineral-soil carbon transport at a number of AmeriFlux sites (FY 2007 and beyond).

4. Collection and analyses of ${ }^{14} \mathrm{C}$ in archived litterfall samples from 2001, 2002, and 2004, and new assessments of wood cellulose ${ }^{14} \mathrm{C}$ for the 2005 and 2006 growing seasons to improve our characterization of the relationship between atmospheric ${ }^{14} \mathrm{C}$ exposures and subsequent tissue accumulations.

5. Extension of the ECHO model to include all mineral soil horizons and its use in probabilistic simulations of the fate of ${ }^{14} \mathrm{C}$ through soils of the Oak Ridge Reservation from 1998 through 2006.

6. Completion of a multi-authored, initial EBIS synthesis manuscript for submission to a high profile journal detailing the nature of soil carbon cycling under eastern deciduous hardwood forests.

7. Aggregate- vs density-based physical separation methods comparison and recommendations for general soil C modeling

8. Reconciliation and comparison of Daycent and RothC models using EBIS data.

9. The first compound specific measures of phospholipid fatty acids will be conducted at UCI. The goal of these measurements is to trace the EBIS litter and root ${ }^{14} \mathrm{C}$ pulses through the microbial community in the $\mathrm{O}$ and A horizons. Equipment for these measurements is being installed at UCI in February 2006. 


\section{EBIS BACKGROUND AND APPROACH}

Purpose of the EBIS Project

A unique, large release of ${ }^{14} \mathrm{CO}_{2}$ occurred near the Oak Ridge Reservation (ORR), Oak Ridge, TN in July/August 1999. At a local level, this pulse label is similar to or larger in magnitude than the pulse of ${ }^{14} \mathrm{C}$ produced by atmospheric weapons testing. Measurements of ${ }^{14} \mathrm{C}$ in tree ring cellulose throughout the ORR area demonstrated that at all sites, the 1999 release was unprecedented in its uptake by vegetation. We are taking advantage of the whole-ecosystem isotopic label generated by this release to address several outstanding issues in the terrestrial carbon cycle:

(1) the partitioning of soil respiration between autotrophic and heterotrophic sources, and quantification of that partitioning seasonally and inter-annually,

(2) the partitioning of heterotrophic respiration sources between aboveground litter decomposition and belowground root detritus decomposition,

(3) the pathways leading from leaf and root detritus to long-term stabilization of soil organic matter, including the role of soil fauna,

(4) the role of dissolved organic carbon (DOC) transport in distributing carbon within the soil profile, and

(5) the longevity and turnover time of fine roots.

Furthermore, we are using the results of our work to parameterize and refine existing carbon dynamics models. Such models will then be used to quantitatively address the long-term fate of ecosystem carbon inputs and the potential for ecosystem carbon sequestration.

\section{Experimental Approach}

The first four issues listed above are being addressed through a reciprocal litter transplant experiment. At four sites on the ORR encompassing two soil types and two levels of ${ }^{14} \mathrm{C}$ exposure in 1999, we established replicated permanent plots for the manipulation of forest litter through reciprocal transplants of enriched versus near back ground litter among sites. With a combination of incubations, soil surface chamber flux measures and soil $\mathrm{CO}_{2}$ profiles, and continuous measurements of soil temperature and moisture controls, we are tracking the changes in soil respiration partitioning over several years of climate variations. The nature and source of long-lived soil organic matter pools are being tracked with differently labeled root and surface litter sources. Experiments to exclude soil fauna will allow understanding of their importance in facilitating those transformation processes. Finally, sampling of soils and soil solutions and the use of inert tracers are enabling us to investigate the chemical nature and form of DOC and its transport in surface soil horizons. By replicating the litter transplant study on two soil types we can address the influence of soil chemical and physical properties on all these issues.

The fifth issue, longevity and turnover of fine roots, was addressed by tracing the radiocarbon label through the fine root pool over time. Doing so will allow us to determine the dynamics of different constituents of the fine root population, as well as their specific contributions (relative to leaf litter) to heterotrophic respiration and soil organic matter formation. Intensive root longevity studies will be conducted at a single site where root samples are available from previous years. 


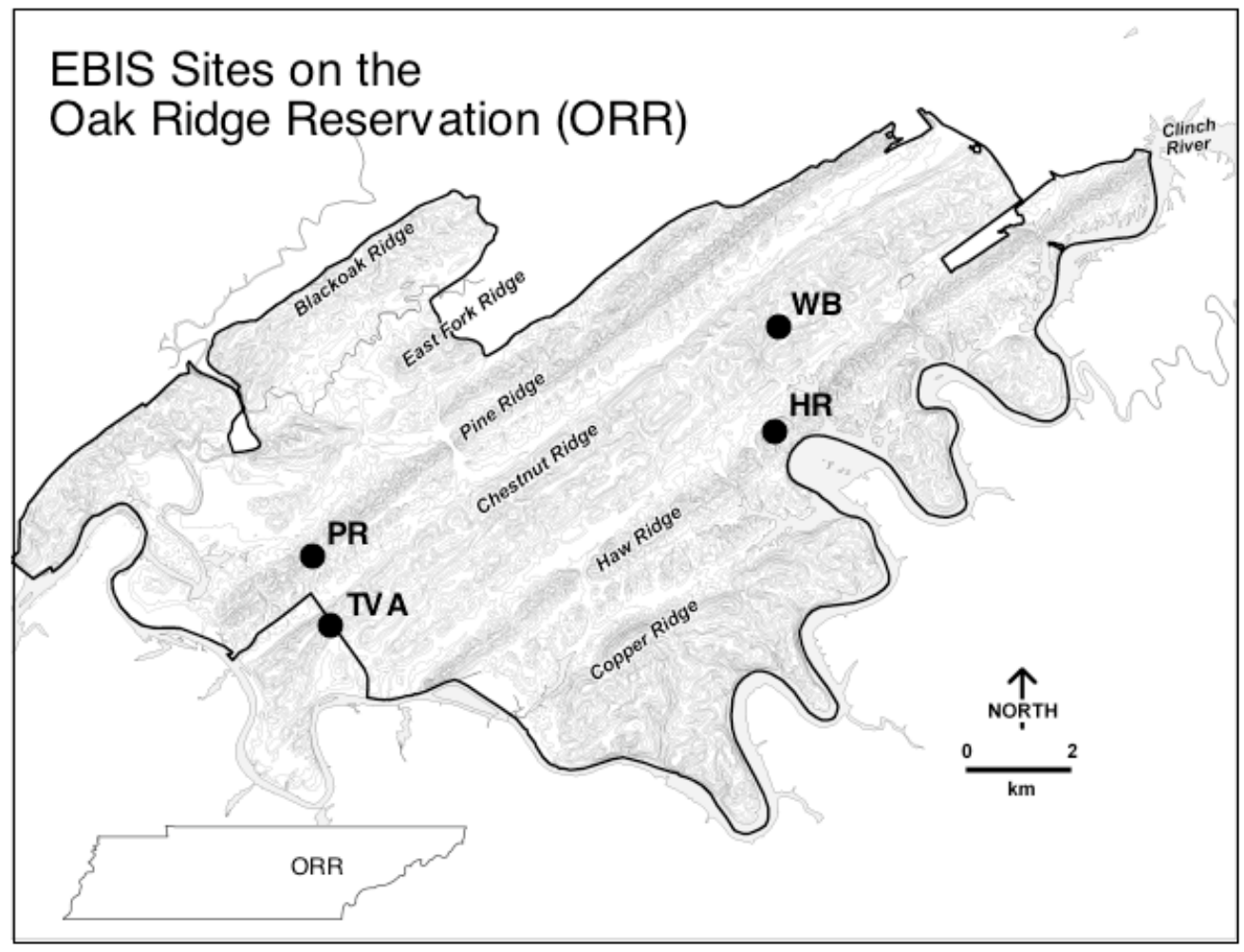

Figure 1. EBIS experimental sites on the Oak Ridge Reservation.

In 2006 we established a replicated mesocosm study designed to track dissolved organic carbon $\left(\mathrm{DO}^{14} \mathrm{C}\right)$ from fresh leaf litter to the Oa and A horizons over 1 to 2 years. This surface pathway was not resolved in the main experiment, but represents a large fraction of the new labile carbon moving through the soil carbon cycle.

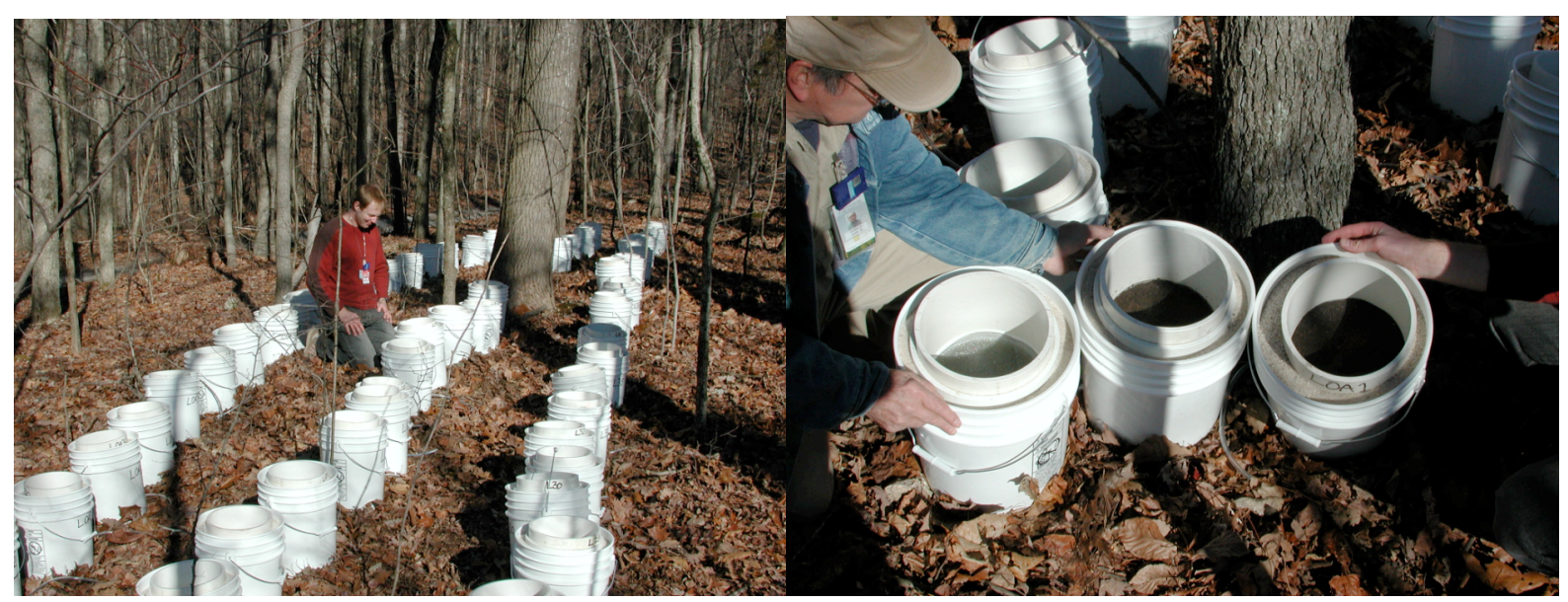

Figure 2. EBIS L- to Oa- to A-horizon mesocosms established February 2006. 


\section{PROGRESS TO DATE \\ A. EBIS Manipulation Study \\ Experimental Litter Manipulations \\ Paul Hanson and Don Todd}

A timeline of experimental activities accomplished since the ${ }^{14} \mathrm{C}$-pulse of 1999 is provided below (Figure 3). As of January 2006 three annual cohorts of either enriched and background litter (collected in the fall of 2000) were applied to the four EBIS experimental plots. Time-zero, $1^{\text {st }}, 2^{\text {nd }}, 3^{\text {rd }}$ and $4^{\text {th }}$-year litter layer and soil core samples from March 2001 January 2002, January 2003, and January 2004, and February 2005 respectively, were collected. All subsamples collected prior to February 2005 have been distributed to individual EBIS researchers for their respective analyses.

Landscape cloth was applied to all experimental plots from mid-October through midDecember in 2000, 2001, and 2002 to exclude ambient leaf litter inputs in those years. In the fall of 2003 and 2004 triplicate $50 \times 50 \mathrm{~cm}$ squares of landscape cloth were added to each plots at the locations for $3^{\text {rd }}$ and $4^{\text {th }}$-year sampling in January of 2004 and 2005, respectively. To avoid excessive sampling of the plots 2006 samples were skipped, but plans are to sample one final time again in January/February of 2007 associated with landscape square deployment in the fall of 2006 .

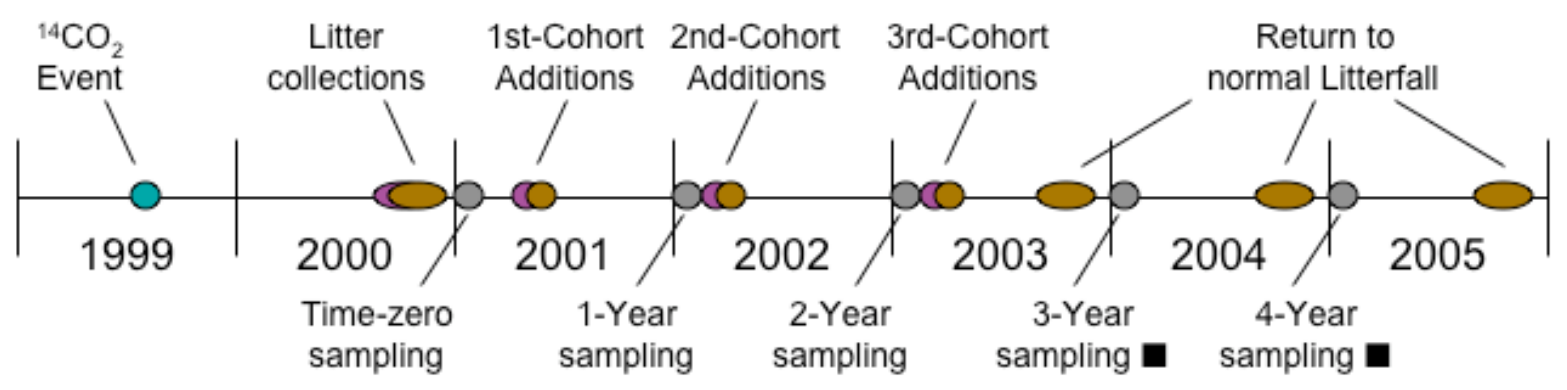

Figure 3. EBIS experimental timeline.

\section{${ }^{14}$ C Analyses \\ Chris Swanston and Tom Guilderson}

Approximately 5000 AMS radiocarbon measurements have been carried out in the first five years of the EBIS project on bulk soil, soil fractions, microbial biomass, dissolved organic carbon, roots, ambient and soil atmosphere, and aboveground biomass in support of all EBIS research tasks. Precision of AMS measurements of graphite from these samples has been high ( $\sim \%$ \%). This large and expensive number of ${ }^{14} \mathrm{C}$ analyses is unprecedented within a single study, but it is necessary as we attempt to appropriately interpret the fate of the $1999{ }^{14} \mathrm{C}$-pulse using a replicated study design and appropriate statistical methods. 


\section{Bulk-Soil ${ }^{14} \mathrm{C}$ Signatures \\ Paul J. Hanson, Chris Swanston, and Donald E. Todd}

Sampling of bulk organic (Oi>1Y and $\mathrm{Oe} / \mathrm{Oa})$ and mineral soil $(0-15,15-30,30-60$, and 60-90 cm) 'horizons' was conducted in January/February 2001, 2002, 2003, 2004, and 2005 representing 0-Year, 1-Year, 2-Year, 3-Year, and 4-Year experimental samples, respectively. Year-zero organic samples were $0.75 \mathrm{~m}^{2}$ per $49-\mathrm{m}^{2}$ plot, but that sampling area was reduced to $0.18 \mathrm{~m}^{2}$ for all subsequent annual measurements. Mineral soil sampling to a target depth of 90 $\mathrm{cm}$ (seldom achieved due to rock and high soil density constraints) were collected over $0.02 \mathrm{~m}^{2}$ of each $49 \mathrm{~m}^{2}$ plot in all years. Through four years of sampling, $<3.7 \%$ of the organic layer and $<0.3 \%$ of the mineral soil available sampling surface $\left(36 \mathrm{~m}^{2}\right)$ has been sampled to date.

After the first year of enriched (1005\%o) or near-background (221\%o) litter additions (2002 data points in Figure 4), recognizable litter greater than 1-year of age (Oi>1Y) showed the expected patterns of enrichment or dilution, respectively. In the western sites (Pine Ridge and TVA) the addition of enriched litter led to a moderate spike in ${ }^{14} \mathrm{C}$-signature of the surface organic layer, and the background litter led to a significant dilution in ${ }^{14} \mathrm{C}$. In the eastern sites (Walker Branch /Haw Ridge), the addition of enriched litter led to a large spike in ${ }^{14} \mathrm{C}$, whereas no change was detectable with the addition of background litter. There was little evidence of new $\mathrm{C}$ movement below the Oi horizon after one year of treatment.

After the second and third year of experimental litter additions, we were surprised to see that ${ }^{14} \mathrm{C}$-signatures of the $\mathrm{Oi}>1 \mathrm{Y}$ layer did not continue to rise in the enriched plots or fall in the near-background litter treated plots (2003 and 2004 data points in Figure 4). Lack of continued increases in the $\mathrm{Oi}>1 \mathrm{Y}^{14} \mathrm{C}$-signature towards the $1000 \%$ bulk signature of the added litter cohorts following three years of treatment was hypothesized and subsequently demonstrated to result from: (1) differential decomposition of individual litter cohorts resulting from inter-annual variations in decomposition driven by variable weather patterns, (2) variable losses of ${ }^{14} \mathrm{C}$ from the metabolism of fresh litter, and (3) variable losses of ${ }^{14} \mathrm{C}$ from leaching of dissolved organic carbon (DOC) from fresh litter. The presence of litter fences, lack of observed mass movement of fresh litter, and consistent plot-to-plot error bars for Oi-layer mass and ${ }^{14} \mathrm{C}$-signatures led us to conclude that localized disturbance was not a contributing factor. Within the Oe/Oa and mineral soil horizons new tissue carbon from root growth and turnover or from $\mathrm{C}$ exudates may have been partly responsible for dilution of the enriched litter.

Through three years of litter manipulation there remained little evidence of new litter-C movement below the Oe/Oa horizon, but enriched litter material had begun to show significant impacts on the Oe/Oa layer by 2004 suggesting a gradual and organized year-by-year migration of litter cohorts into the humus layer. Even though rapid and significant leaching of dissolved organic carbon is expected from fresh leaf litterfall, this material may not be accumulating within the surface mineral soils for several reasons. The large stocks of soil $\mathrm{C}$ in the surface soil, high variability of the soil matrix, may obscuring our ability to detect the downward movement of ${ }^{14} \mathrm{C}$ signal into the large carbon pool of the $0-15 \mathrm{~cm}$ soil layers. In addition, the leachable fraction of fresh litterfall may be of a predominantly labile form that is consumed within a one-year cycle (our temporal level of detection for this work). A new mesocosm study discussed later on has been initiated to measured intra-annual patterns of vertical DOC transport to reconcile these issues. 

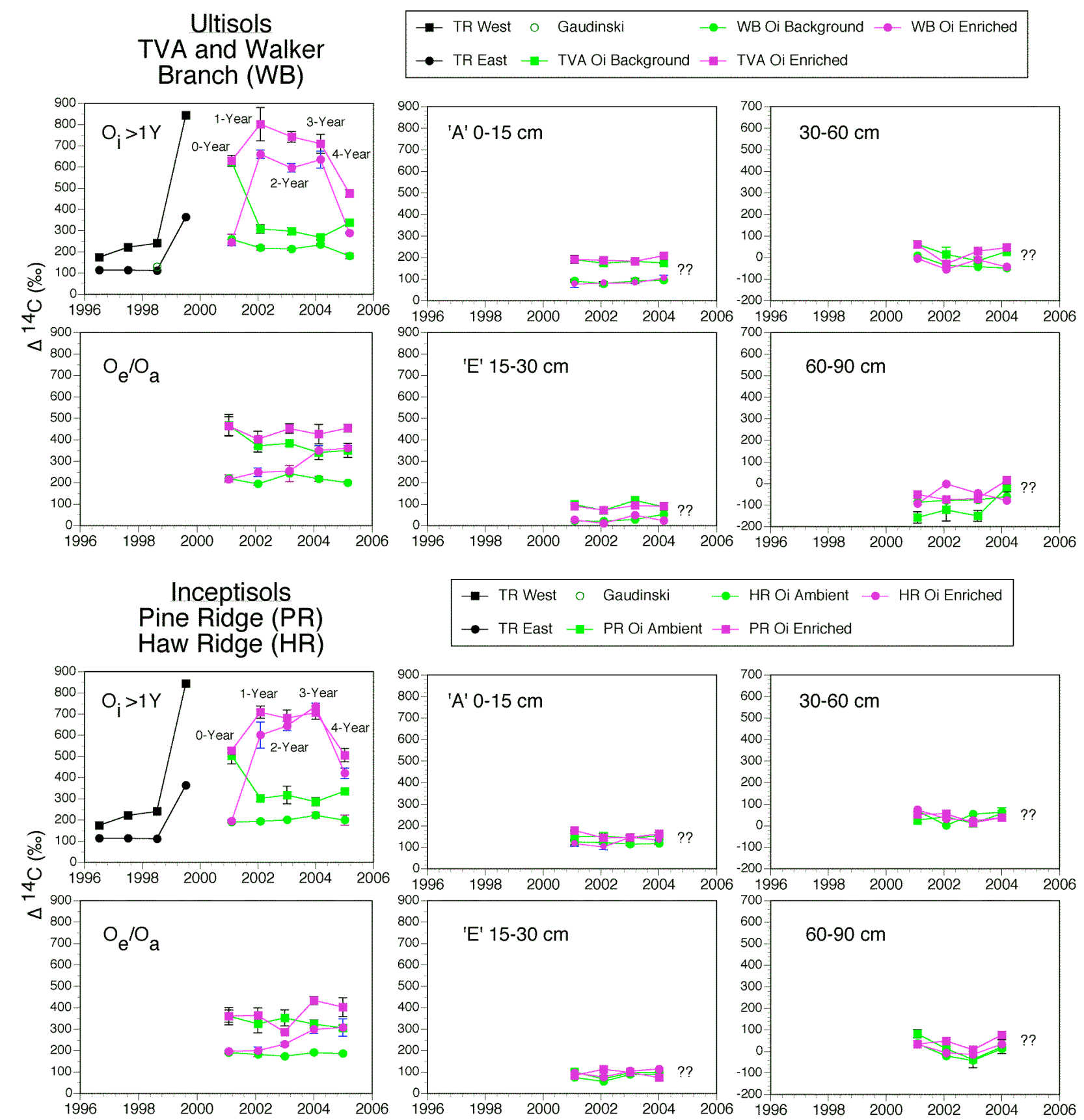

Figure 4. Bulk ${ }^{14} \mathrm{C}$-analysis by site and horizon for the Ultisol (upper graph) and Inceptisol (lower graph) sites showing the following layers: recognizable litter $(\mathrm{Oi}>1 \mathrm{Y})$, humus layer including some root material (Oe/Oa), 0 to $15 \mathrm{~cm}$ mineral soil (0-15), 15 to $30 \mathrm{~cm}$ mineral soil (15-30), 30 to $60 \mathrm{~cm}$ mineral soil (30-60), and 60 to $90 \mathrm{~cm}$ mineral soil (60-90). Black symbols are the ${ }^{14} \mathrm{C}$ in tree ring cellulose (TR) for the years prior to time-zero that are assumed to reflect litterfall ${ }^{14} \mathrm{C}$-signatures for those periods. 


\section{Air Monitoring of ${ }^{14} \mathrm{C}$}

Susan E. Trumbore et al.

The ${ }^{14} \mathrm{C}$ in sub-canopy air has been monitored during the growing season at Walker Branch and Pine Ridge/TVA sites since September 2000 (Figure 5). Air samples were collected approximately $1 \mathrm{~m}$ above ground by slowly filling an evacuated 32-liter canister over a twoweek period through a capillary restrictor. The data are 2-week averages, likely biased towards nighttime $\mathrm{CO}_{2}$ values when local inversions are associated with higher $\mathrm{CO}_{2}$ concentrations at the ground.

\section{Signatures of ${ }^{14} \mathrm{C}$ in Two-week Air Samples 2 . WB and HR Air}

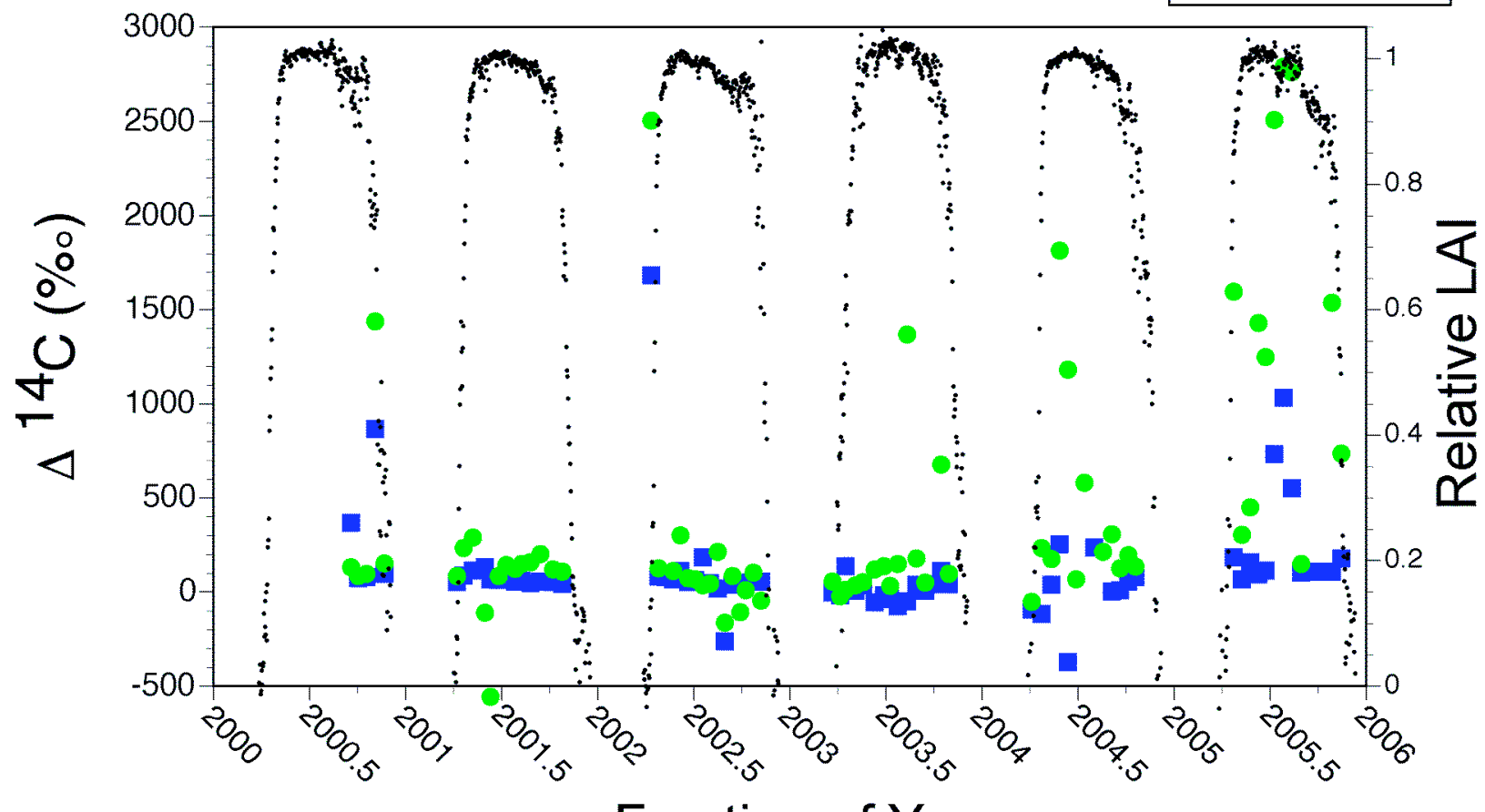

\section{Fraction of Year}

Figure 5. ${ }^{14} \mathrm{C}$ in ambient air $\mathrm{CO}_{2}$ representative of eastern (Walker Branch WB; Haw Ridge HR) and western (Pine Ridge PR; TVA) on the Oak Ridge Reservation.

High ${ }^{14} \mathrm{C}$ levels at both sites, indicative of new ${ }^{14} \mathrm{C}$ releases, were observed in early November 2000, mid-April, 2002, August of 2003 and during multiple events in both 2004 and 2005. The air ${ }^{14} \mathrm{C}$-values are typically higher at Pine Ridge than at Walker Branch. The ${ }^{14} \mathrm{C}$ release in November 2000 took place after leave senescence, and thus was likely not incorporated into plants. The April 2002 release occurred at the beginning of canopy leaf development, but samples of oak leaves and squaw root plants in early May (approximately 15 days after the event) showed no evidence of incorporation of the elevated ${ }^{14} \mathrm{C}$ from this atmospheric peak. The August 2003 release in the vicinity of Pine Ridge was incorporated by photosynthesis of the 'west-end' forest canopy, and 2003 canopy litter fall showed west-end TVA and PR litterfall to be enriched with respect to litterfall at WB and HR ( 208 vs. $107 \%$, respectively). That enrichment, however, may also result from residual multi-year exposures to ${ }^{14} \mathrm{C}$ since 1995 . Notwithstanding the pulses of ${ }^{14} \mathrm{C}$ received by the forest ecosystems in late 2003 , 
the air monitoring data shows that our analysis and modeling of the fate of enriched vs. nearbackground litter additions from 2001 through the third year of stable 2000-cohort additions in 2003 will be largely unaffected. Conversely, the magnitude of the summer ${ }^{14} \mathrm{C}$-pulses in 2004 and 2005 have had a significant effect on west-end tissue ${ }^{14} \mathrm{C}$-signature and those implications will be discussed in the next section.

\section{Temporal Trends of ${ }^{14} \mathrm{C}$ in Plant Tissues \\ Chris Swanston, Susan Trumbore, Margaret Torn, and Paul J. Hanson}

Assessments of ${ }^{14} \mathrm{C}$ within tree ring cellulose were conducted to generate a comprehensive site-by-site record of the ${ }^{14} \mathrm{C}$ history of the Oak Ridge Reservation. Duplicate increment cores $5 \mathrm{~mm}$ in diameter for $Q$. alba and $Q$. prinus trees were collected in July of 2004. Rings were removed in 1-year or 1/3 year increments. Rings representing the growing season of calendar years 2003 to 1999 were each separated into thirds. Years 2004, 1998 - 1990, 1985, and 1980 were collected as complete years. Soxhlet extractions were carried out on a subset of about 100 'thirds' and rings, sufficient to characterize the major atmospheric fluctuations at the EBIS sites. The method, adapted from that used by Julia Gaudinski on root samples, extracted holocellulose by boiling in a 2:1 mixture of toluene and ethyl alcohol for $24 \mathrm{hr}$, followed by another $24 \mathrm{hr}$ in ethyl alcohol, before the samples were bleached in a sonic bath with acetic acid and sodium chlorite. The extracted cellulose was then converted to graphite using the standard hydrogen-reduction method.

Figure 6 shows ${ }^{14} \mathrm{C}$ signatures of tissue of western (TVA and Pine Ridge) and eastern (Walker Branch and Haw Ridge) sites on the Oak Ridge Reservation. The data appropriately demonstrate the presence of ${ }^{14} \mathrm{C}$ exposures in 1999 and perhaps early 2000, and show that

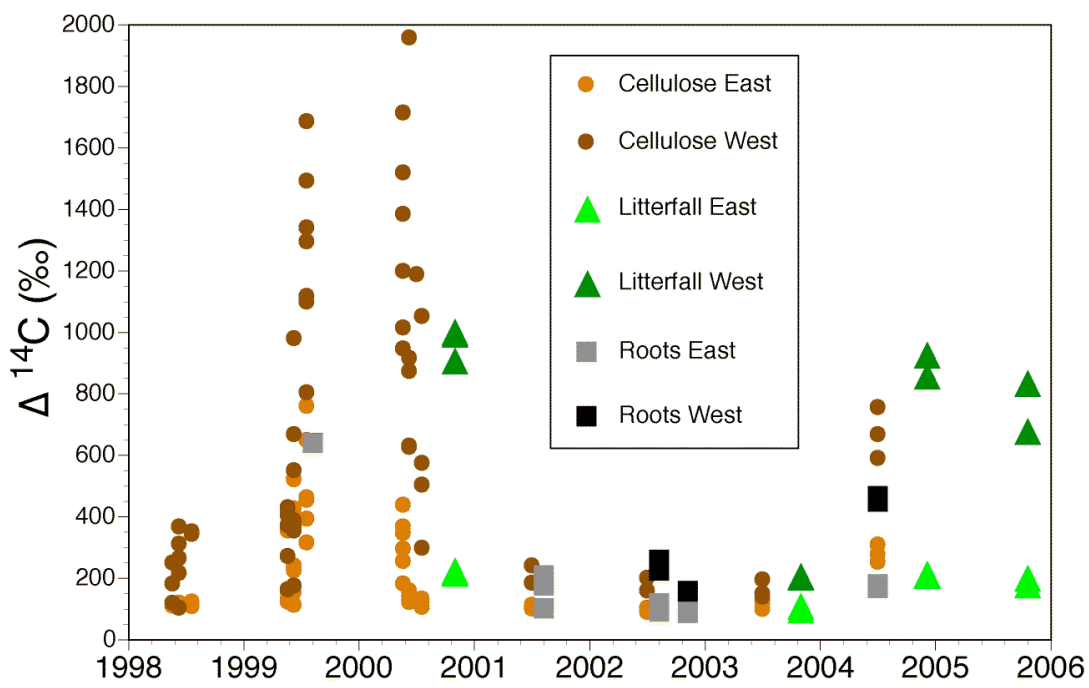

Figure 6. The ${ }^{14} \mathrm{C}$-signatures for Quercus alba wood holocellulose and selected leaf litter and fine root samples from 1990 through 2005 demonstrating the importance of the original $1999{ }^{14} \mathrm{C}$ pulse and more recent 2004 and 2005 pulses on the ${ }^{14} \mathrm{C}$-signature of recent tissue growth.

vegetation on the western end of the ORR (TVA and PR) experience elevated ${ }^{14} \mathrm{C}$ prior to the 1999 pulse. These tissue data are in general agreement with the ${ }^{14} \mathrm{C}$-air measurements for 2000 to 2003 (Figure 6), but they also show the influence of the 2004 and 2005 mid-summer ${ }^{14} \mathrm{C}$ 
pulses to biological processes. Interestingly, however, the greater concentration of ${ }^{14} \mathrm{C}$ spikes in 2005 did not yield litterfall with a higher ${ }^{14} \mathrm{C}$-signature. Additional samples of 2005 root growth and wood cellulose will be collected and assayed to better characterize the relationship between atmospheric exposure to $\mathrm{CO}_{2}$ and tissue ${ }^{14} \mathrm{C}$-signatures.

Summertime releases of ${ }^{14} \mathrm{C}$ in May, June, and July of 2004 were responsible for enriching current photosynthate in 2004, and were incorporated into new root growth at both western and (to a lesser extend) eastern sites (Figure 7). Carbon dioxide at the Walker Branch measurement site is periodically impacted by a local fossil fuel source leading to substantially negative ${ }^{14} \mathrm{C}$ numbers. Root respiration ${ }^{14} \mathrm{C}$ also shows small increases following the August 2003 release at both sites, and large increases at both sites in early 2004. Interestingly, the root respired $\mathrm{CO}_{2}$ values returned to earlier levels in August 2004, which may be an indication of either a switch in the pools used to fuel root respiration or the time it took for the new release to move through respirable $\mathrm{C}$ pools. Early gas-well data contrasting ${ }^{14} \mathrm{C}$-signatures beneath background and enriched litter plots also suggests rapid downward vertical transport of ${ }^{14} \mathrm{C}$ into the upper mineral horizons, but insignificant changes in the bulk ${ }^{14} \mathrm{C}$ levels of the surface mineral soils suggests that much of the transported carbon may be subsequently lost to microbial decomposition
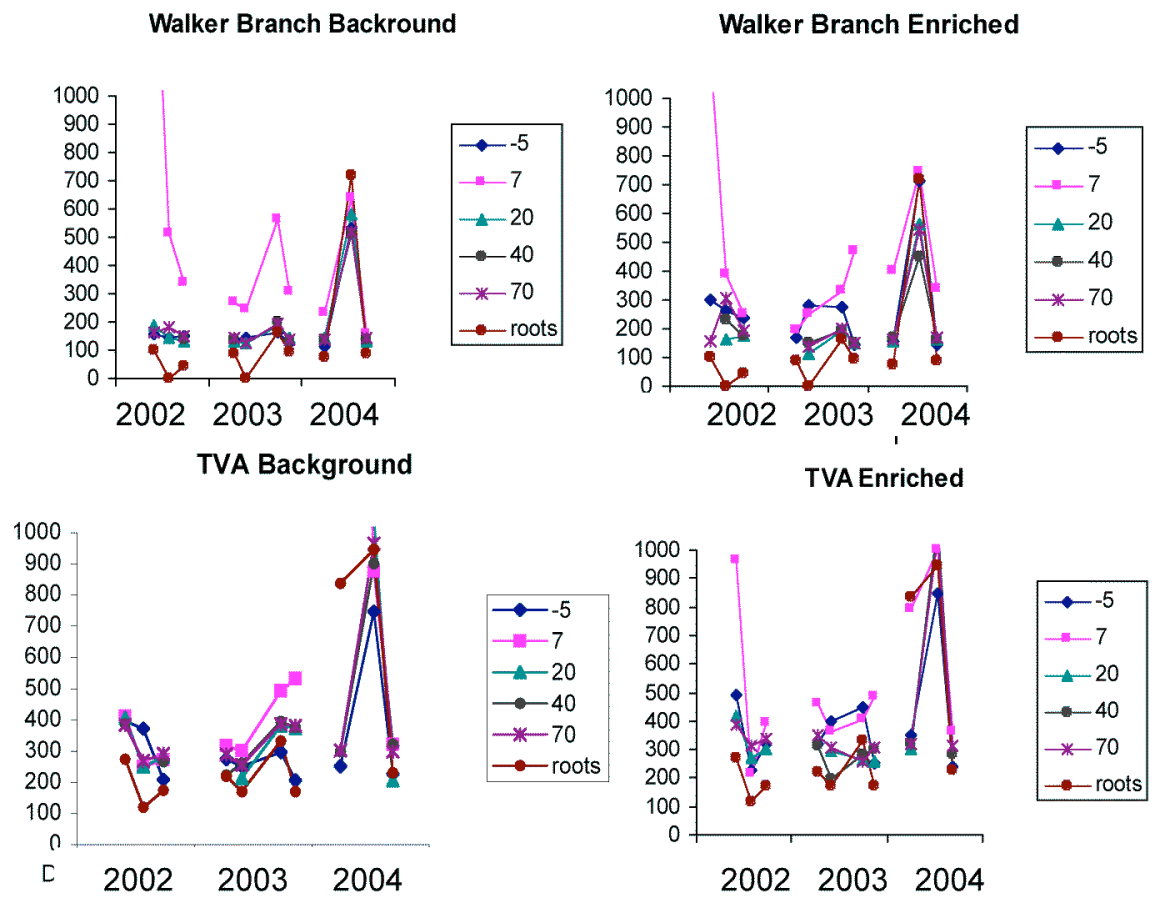

Figure 7. Pattern of ${ }^{14} \mathrm{C}$ in 'roots' or from gas wells within the soil for collection on the east (Walker Branch) or west (TVA) end of the Oak Ridge Reservation. 


\section{Chemical fractions of ${ }^{14} \mathrm{C}$-content of fresh litter}

Laura J. Hainsworth and Chris Swanston

Analysis of the ${ }^{14} \mathrm{C}$ content of various carbon chemical pools in the 2000 leaf-litter-cohort was initiated to gain a better understanding of the nature of the pulse-labeling event and the distribution of the radiocarbon label within the foliar litter. Variations in the ${ }^{14} \mathrm{C}$-content of carbon pools within the leaf litter were hypothesized as one mechanism to explain the multi-year stabilization of the ${ }^{14} \mathrm{C}$-signatures of the Oi horizon. An initial laboratory experiment was conducted on enriched and near-background Quercus prinus L. litter collected in 2000 to determine if leaching of fresh litter would yield DOC with a different ${ }^{14} \mathrm{C}$-signature from the original bulk material. That study showed the mean water-soluble leachate [C] to be $378 \mu \mathrm{g} \mathrm{cm}^{-3}$ and did not differ by source of the litter source (near-background vs. enriched). Near-background tissues showed uniform ${ }^{14} \mathrm{C}$-signatures for leached and bulk tissues, but the soluble materials leaching from enriched litter had a significantly higher ${ }^{14} \mathrm{C}$-signatures $(\mathrm{p}=0.02)$. This previously unrecognized phenomenon proved to be critical to modeling ${ }^{14} \mathrm{C}$ movement through the organic and mineral soil horizons. In an effort to better characterize the allocation of the radiocarbon label in the litter, a series of chemical fractionations are being analyzed for litter from three dominant species: Q. prinus, Q. alba L., and Acer rubrum L. Samples were obtained from the archived near-background (Walker Branch) and enriched (Pine Ridge) 2000 litterfall cohorts. Isolation of soluble components (sugars, amino acids and soluble phenolic compounds) and insoluble residue (cellulose and lignin) from ground leaf tissue was done (Figure 8).

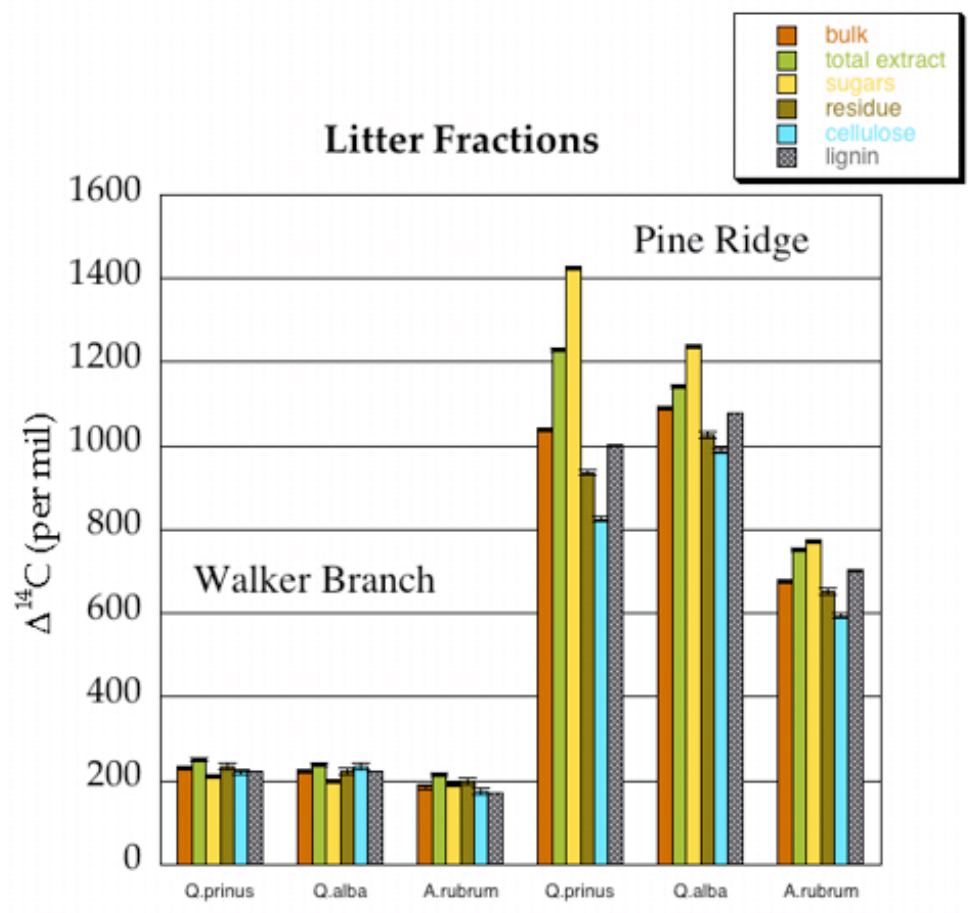

Figure $8 .{ }^{14} \mathrm{C}$-signature of chemical fractions in near-background and enriched Acer rubrum, Quercus prinus and Quercus alba litter. 
These detailed analyses confirm the observations made in the simple leaching experiment. Soluble compounds show significant ${ }^{14} \mathrm{C}$ enrichment over the insoluble, structural compounds in the enriched 2000 litter cohort, and similar (albeit small) differences were present in the near-background cohort suggesting a consistent mechanism. The level of litter enrichment was found to depend on species, with $Q$. prinus and $Q$. alba exhibiting greater isotopic enrichment than A. rubrum litter. Preferential loss of enriched, soluble material from leaching and/or microbial decomposition reduces the ${ }^{14} \mathrm{C}$-signature of the residual organic matter of the $\mathrm{Oi}>1 \mathrm{Y}$ horizon. The stabilized Oi-horizon ${ }^{14} \mathrm{C}$-signatures after three years of litter manipulations (Figure 4) reach values approximate the mean signatures for residue, cellulose, and lignin chemical forms averaged across the source species. Mass balances will be completed for the sample fractions, and these data will be used to improve our simulations of $\mathrm{C}$ cycling via the processes of leaching and annual, downward vertical migration of litter cohort residue.

\section{Soil C Dynamics in Unprotected and Protected Pools: Aggregated-based fractionations}

Julie Jastrow, Sarah O’Brien, Kelly Moran, and Chris Swanston

For the purpose of tracking the movement of input sources into stabilized $\mathrm{C}$ pools, we fractionated mineral soil (A horizon; 0-15 cm) from three of the four treatments: CONTROL (background litter/background roots), LITTER (enriched litter/background roots), and ROOTS (background litter/enriched roots) in both Inceptisols (HR and PR) and Ultisols (WB and TVA). Samples collected in 2001, 2002, and 2003 (i.e., Year 0, Year 1, and Year 2) were physically fractionated into unprotected and microaggregate-protected particulate organic matter (POM and $\mathrm{mPOM}$ ), microaggregated silt and clay (mSILT and mCLAY), and silt and clay not associated with microaggregates (SILT and CLAY). In addition, all silt and clay fractions were chemically fractionated by acid hydrolysis. Samples from Year 3 are currently in the process of being fractionated both physically and chemically.

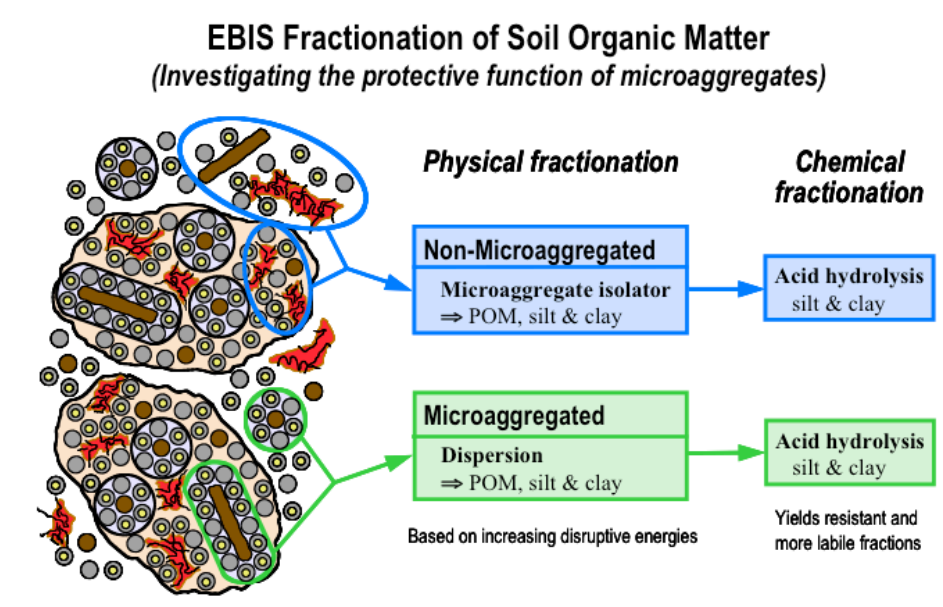

Figure 9. Aggregate-based physical separation scheme for characterizing soil carbon fractions with respect to their mean turnover times.

Taken together, POM and mPOM contained about $50-60 \%$ of the total soil organic carbon in both soil types, whereas SILT plus mSILT and CLAY plus mCLAY composed 30$40 \%$ and $\sim 10 \%$ of total soil organic carbon, respectively. Of the carbon, $38-52 \%$ in silt-sized 
fractions and 46-63\% in clay-sized fractions was hydrolyzable. Ratios of C: $\mathrm{N}$ in the various fractions decreased with decreasing particle size, consistent with the inverse relationship between particle size and degree of rendering observed in many soils. The narrow $\mathrm{C}: \mathrm{N}$ ratios of the hydrolysable fractions suggest that these fractions could include microbial biomass and byproducts, as well as amino compounds and other nitrogen-rich materials, in addition to polysaccharides. The $\mathrm{C}: \mathrm{N}$ ratios of the acid-resistant fractions were much broader than those of POM, suggesting this material includes a mixture of aromatic humic materials and plant residue lignin, lignin derivatives, and lignin-associated cellulose from recent plant residues.

As expected, POM had the highest ${ }^{14} \mathrm{C}$ enrichment in all treatments for both soil types (Figure 10). This fraction is the least degraded and the freshest of all fractions and is composed largely of root fragments and other pieces of organic debris. In the LITTER treatment, the ${ }^{14} \mathrm{C}$ signatures of most fractions differed little from those found in the CONTROL. However, by Year-2 it appears that the ${ }^{14} \mathrm{C}$ signature of CLAY is increasing relative to the CONTROL in both soils and may indicate movement of small amounts of dissolved or colloidal organic $\mathrm{C}$ from the labeled surface litter. Since the clay-sized fractions contain the smallest proportion of the total soil $\mathrm{C}$, it will take less LITTER-derived ${ }^{14} \mathrm{C}$ to change the signature of this fraction.

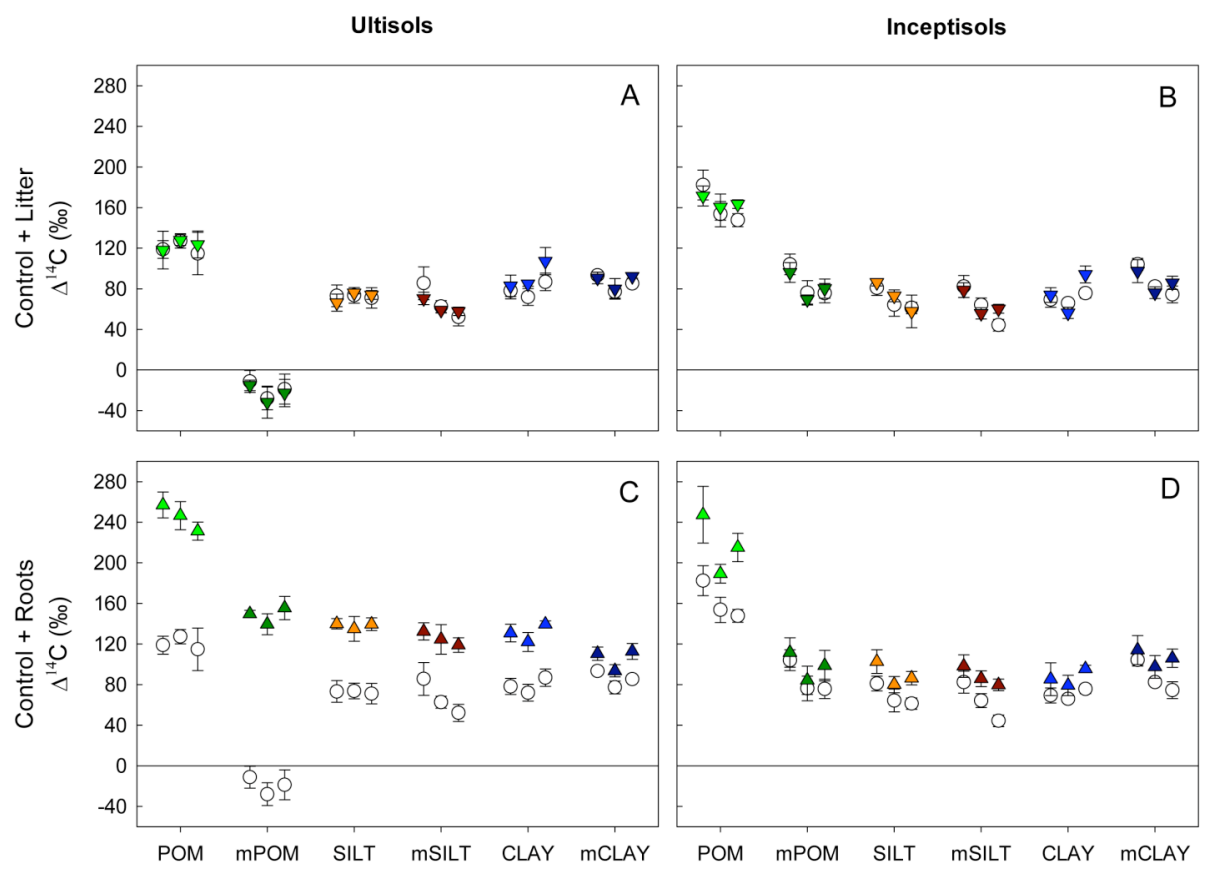

Figure 10. Mean $( \pm \mathrm{SE}) \Delta^{14} \mathrm{C}$ for physically isolated fractions in (A \& B) LITTER and (C \& D) ROOTS treatments for both soils. CONTROL values are shown as open circles for comparison.

Most fractions had higher ${ }^{14} \mathrm{C}$ signatures in the ROOTS plots than in the CONTROL, especially for the Ultisols. Radiocarbon in Ultisol POM declined as expected, but no clear trends have emerged for this fraction in the Inceptisol. However, all three microaggregated fractions in the ROOTS plots showed consistent ${ }^{14} \mathrm{C}$ enrichment relative to CONTROLS in both soils (Figure 11). In contrast, non-microaggregated SILT and CLAY do not appear to be changing, even though these fractions achieved some level of ${ }^{14} \mathrm{C}$ enrichment before the experiment started. This finding is consistent with conceptual models of the cycling of root-derived inputs through soil microaggregates. 

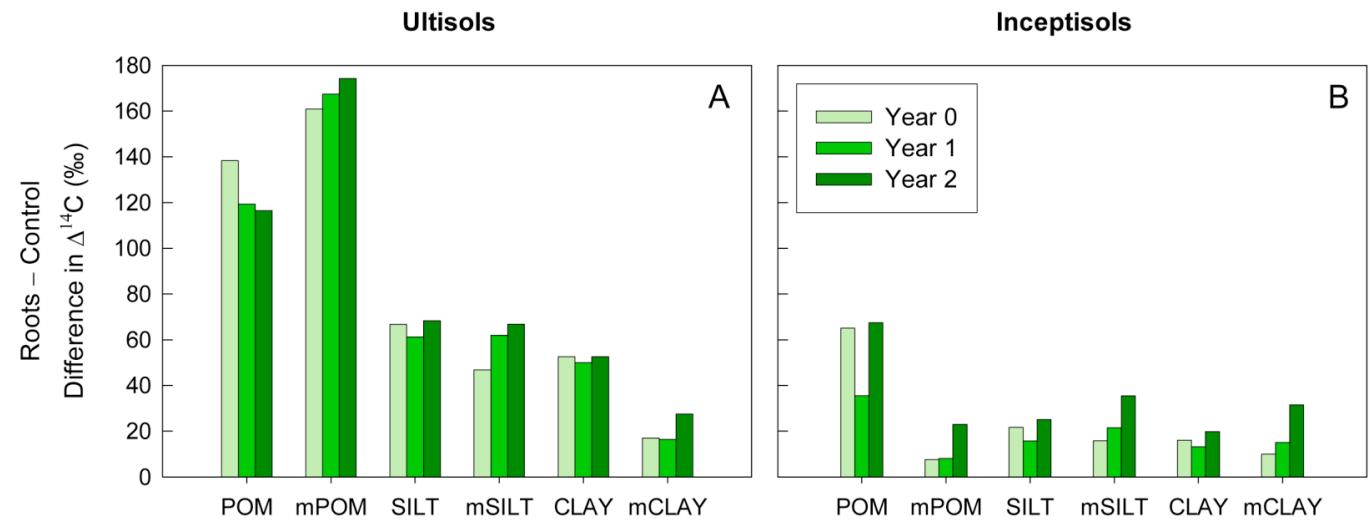

Figure 11. Differences relative to the CONTROL for the $\Delta^{14} \mathrm{C}$ of physically isolated fractions in the ROOTS treatments over time for each soil type.

Acid hydrolysis of silt- and clay-sized particles (Figure 12) clearly separated two fractions with different ${ }^{14} \mathrm{C}$ signatures. The acid resistant fractions generally had ${ }^{14} \mathrm{C}$ signatures near zero or below. Surprisingly, hydrolyzable $\mathrm{C}$ in all mineral fractions had ${ }^{14} \mathrm{C}$ signatures that were similar to those of the POM in the ROOTS treatment. Thus, in both CONTROL and LITTER treatments radiocarbon was considerably higher in hydrolyzable mineral-associated C than in POM, supporting root modeling results that suggest the east side of the Oak Ridge Reservation may have been exposed to a higher atmospheric ${ }^{14} \mathrm{C}$ pulse than originally thought. Losses of ${ }^{14} \mathrm{C}$ from hydrolyzable silt-sized particles over time were accompanied by increases in the ${ }^{14} \mathrm{C}$ signatures of acid resistant silt fractions in all Ultisol treatments and the ROOTS treatment for Inceptisols. This finding suggests that more of the root residues likely contributing to this pool are becoming more degraded and humified with time, and thus more resistant to hydrolysis. Although ${ }^{14} \mathrm{C}$ signatures in hydrolyzable clay-sized fractions do not show clear trends, radiocarbon is increasing in the acid resistant clay-sized fractions of the ROOTS treatment in both soils and the LITTER treatment in the Inceptisol. These results further demonstrate the presence of a highly dynamic component in the acid-resistant pools.

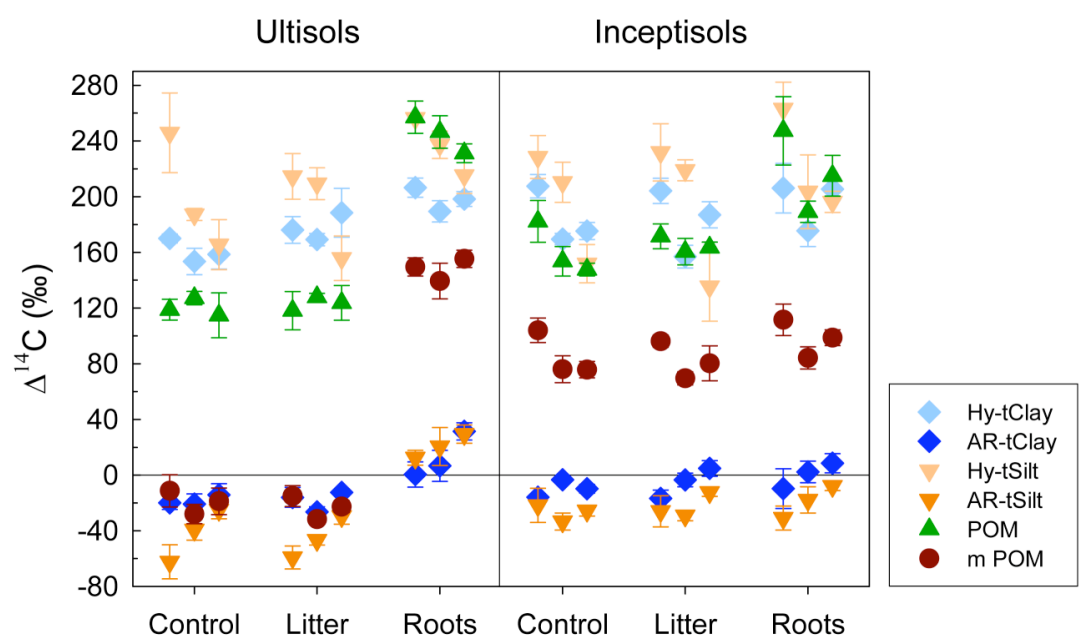

Figure 12. Mean ( $\pm \mathrm{SE}) \Delta{ }^{14} \mathrm{C}$ for physically and chemically isolated fractions from both soils. Total silt- and claysized particles are further fractionated by acid hydrolysis to yield hydrolysable (Hy) and acid resistant (AR) components. 


\section{Forms and fate of carbon in soils: density-based method Chris Swanston and Margaret Torn}

The density-based soil fractionation scheme was effective in describing carbon dynamics (Swanston et al. 2005). Free light fractions (free LF) are isolated primarily from inter-aggregate spaces, and represent the most plant-like and rapidly cycling soil organic fraction. The occluded light fraction (occluded LF) is isolated primarily from within aggregates, and appears to primarily consist of free LF that has become entrained by soil minerals to form stable aggregates. The dense fraction is primarily non-particulate $\mathrm{C}$ associated with minerals. To date we have completed analysis of 0-15 cm soils for time- zero, 1- year, 2- year, and 3- year; 15-30 cm soils for time- zero and 1- year, and 30-60 cm soils for 1- year samples.

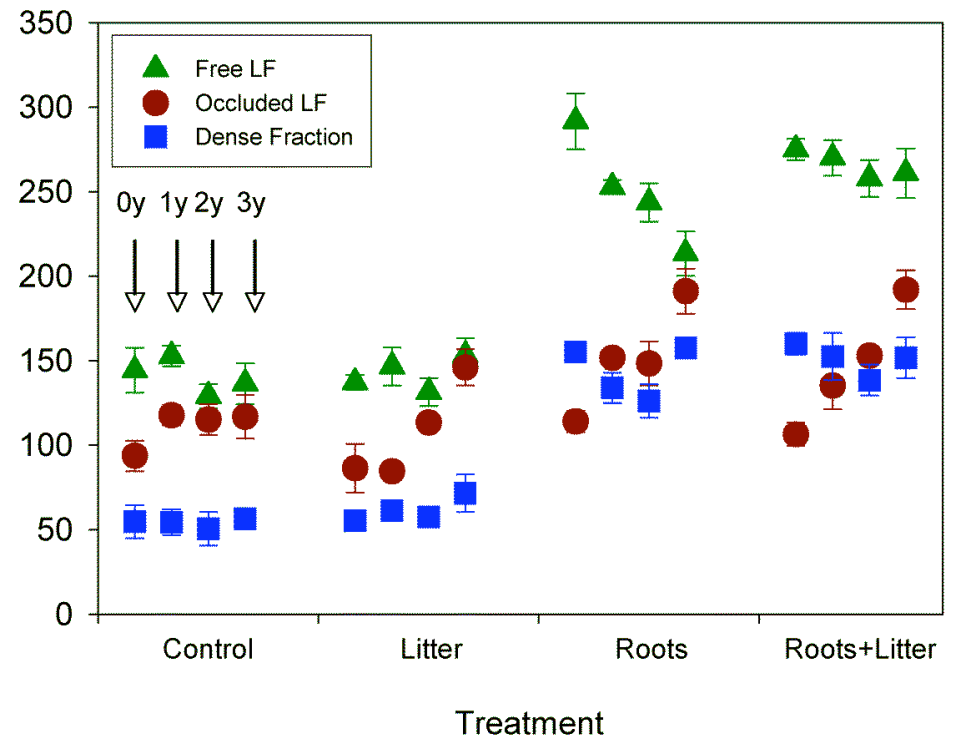

Figure 13. ${ }^{14} \mathrm{C}$-signature of density-based fractions of $0-15 \mathrm{~cm}$ Ultisol soils during the first three years of the EBIS litterfall manipulations. 'Root' effects during this period are limited to the declining influence of the initial $1999{ }^{14} \mathrm{C}$ pulse, and were not renewed yearly.

The Ultisols at western sites show a clear decrease in the $\Delta^{14} \mathrm{C}$ of free light fraction over time, presumably from the loss and dilution of ${ }^{14} \mathrm{C}$ derived from the initial $1999{ }^{14} \mathrm{C}$ inputs ('Root' treatment). The loss of the ${ }^{14} \mathrm{C}$ is at least partly due to incorporation of the ${ }^{14} \mathrm{C}$-enriched free LF into the occluded fraction, which shows increasing $\Delta^{14} \mathrm{C}$ through time. These results represent the clearest validation to date of the conceptual model of $\mathrm{C}$ cycling and aggregate formation associated with this method. The dilution of $\Delta^{14} \mathrm{C}$ in the free LF appears to be muted by the addition of enriched surface litter ('Root+Litter' treatment), indicating some ${ }^{14} \mathrm{C}$ inputs from the added litter.

The dense fraction shows little change over three years relative to the light fractions, but nonetheless shows more change than expected from a 'stable' fraction. Further separation of active and stable components within this fraction by Kleber et al. will address this. The Inceptisols show fewer trends, possibly as a result of faster mixing and organic matter decomposition. We conclude that there appears to be almost no time lag between the ${ }^{14} \mathrm{C}$ enrichment of plant root biomass and incorporation of the ${ }^{14} \mathrm{C}$ into the free light fraction, but a significant lag for incorporation into the occluded light fraction. 


\section{Observations on Soil Mineralogy \\ Markus Kleber, Margaret Torn, and Chris Swanston}

The mineral matrix of the Ultisol and Inceptisol soils were evaluated because the organic carbon of dense soil fractions is viewed as being closely associated with minerals, and such associations are considered indicative of the amount of stable, protected, slow cycling carbon within soils. Further characterization of the operational soil carbon pools (e.g., aggregate or density based fractions) was viewed as a means to interpret the functionality of these 'defined' pools to make them more useful in the context of soil carbon cycling models. These characterizations also allowed the uniformity of the replicate Ultisol and Inceptisol sites on the Oak Ridge Reservation to be evaluated.

X-ray diffraction analysis showed both soil types to be highly weathered, an absence of their respective primary minerals, and domination of the mineral composition by residual quartz. In contrast to previous hypotheses regarding a greater capacity of Ultisol B-horizon soils to sequester carbon, this analysis suggested that the Inceptisols showed greater variety in mineral assemblage and greater potential for development of reactive surfaces. Based on X-ray diffraction TVA soils were identical to those at Walker Branch and that Pine and Haw Ridge soils were very similar. Haw Ridge soils had the "richest" mineralogy.

Other analyses indicated that the eastern soils (WB, HR) contained more pedogenic iron oxides than the western soils (PR, TVA), but in the context of soils across the globe these Ultisols and Inceptisols exhibited a low iron activity ratio (Feo/d) and are pedogenetically inactive. From a mineralogical point of view there is no reason to assume that these soils should be able to retain significant amounts of downward percolating suspended/dissolved organic carbon. Therefore, these data lead to the hypothesis that soil texture driven preferential flow pathways should be the dominant pathway for vertical transport of colloidal carbon into deep soils. Further evaluations are planned to determine mineralogical properties of density fractions, test hypothesis that both ${ }^{14} \mathrm{C}$ label and reactive mineral surfaces occur together within dense (sub)fractions, determine mechanism of label retention, and to pass these mechanisms to the EBIS modeling teams.

Inceptisols

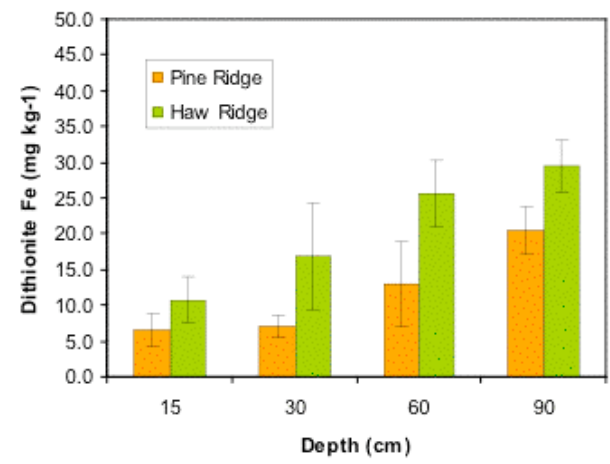

Ultisols

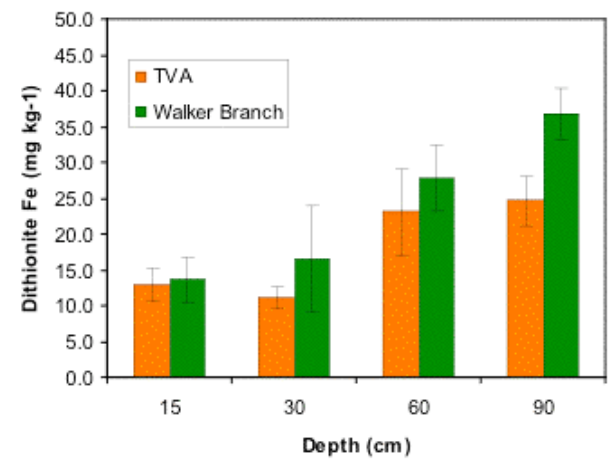

Figure 14. Index of iron oxide presences by soil type and depth. 


\section{Microbial Biomass ${ }^{14} \mathrm{C}$ \\ Margaret Torn et al.}

Microbial biomass ${ }^{14} \mathrm{C}$ showed treatments effects after only two years of treatments. In the mineral soil, microbial biomass ${ }^{14} \mathrm{C}$ was much higher where the root substrate was ${ }^{14} \mathrm{C}$-labeled. The $\mathrm{O}$ horizon microbial biomass was enriched by the litter treatment (Figure 15), showing the lack of effect in mineral soil was not due to artifacts or time lags between utilization and labeling of the biomass. These observations support the hypothesis that root inputs are more important source of $\mathrm{C}$ than are leaf litter inputs in these temperate forest soils, during the first four years after litter input.

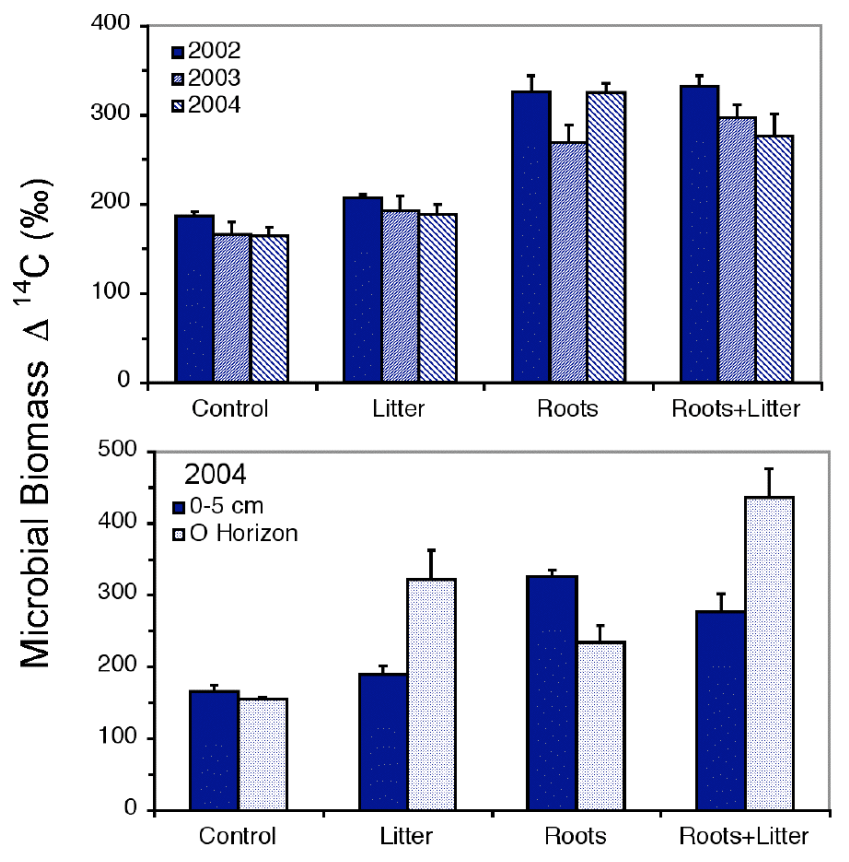

Figure 15. Upper panel: Microbial biomass ${ }^{14} \mathrm{C}$ of A horizon in 2002, 2003, and 2004. Samples collected at $0-10 \mathrm{~cm}$ in 2002 and 0 $5 \mathrm{~cm}$ thereafter. Lower panel: Microbial biomass ${ }^{14} \mathrm{C}$ of $\mathrm{A}$ horizon and $\mathrm{O}$ horizon (Oi, Oe/a) in 2004. The x-axis shows the source of radiocarbon enrichment at the site (corresponds to WBB, WBE, TVAB, TVAE where subscript $\mathrm{B}=$ background and $\mathrm{E}=$ enriched litter treatment. 


\section{Tracer ${ }^{15} \mathrm{~N}$ and Natural Abundance ${ }^{13} \mathrm{C}$ Studies at EBIS Sites}

Charles T. Garten et al.

$\mathrm{NH}_{4^{-}}{ }^{15} \mathrm{~N}$ tracers were used to study fate of $\mathrm{N}$ for the Inceptisol and Ultisol soils. Five applications of $\mathrm{NH}_{4}{ }^{-15} \mathrm{~N}$ (9 atom \%) were made over 14 weeks in 2004. This application was equivalent to $\approx 50 \%$ of $\mathrm{N}$ deposition in annual precipitation. The recovery of ${ }^{15} \mathrm{~N}$ tracer was $\approx 70 \%$ at 6 weeks following last application. Most of the ${ }^{15} \mathrm{~N}$ was retained in forest floor (F) and surface soil (S) with $\leq 2 \%$ of the applied ${ }^{15} \mathrm{~N}$ found in roots from litter and surface soils. High $\mathrm{NH}_{4}{ }^{-}{ }^{15} \mathrm{~N}$ recovery and long $15 \mathrm{~N}$-tracer retention times indicated the forest floor was an effective filter for atmospheric $\mathrm{N}$ inputs moving into the mineral soil at all sites.
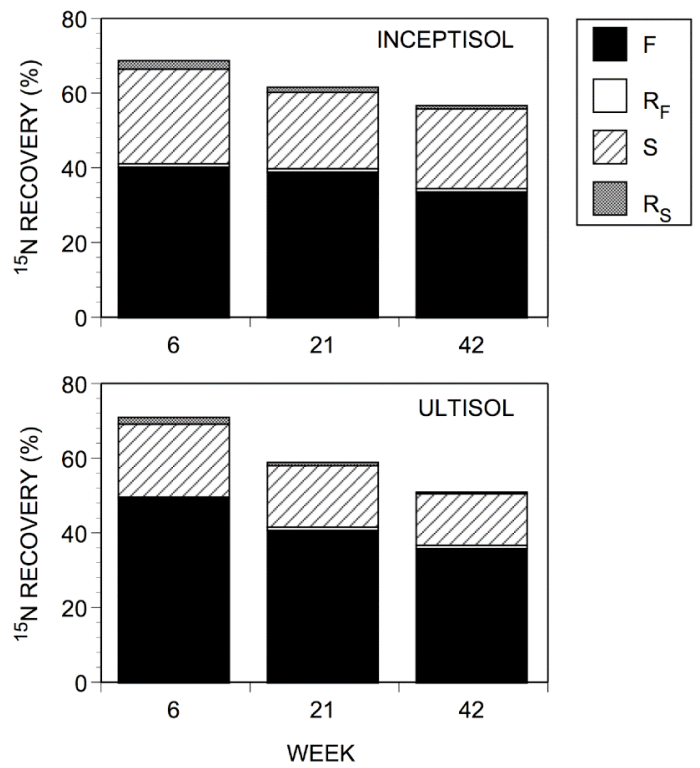

Figure 16. Recovery of ${ }^{15} \mathrm{~N}$ tracer in root-free forest floor $(\mathrm{F})$, fine roots from forest floor (RF), fine roots from soil (RS), and mineral soil (S) at 6, 21, and 42 weeks after $\mathrm{NH}_{4}{ }^{-15} \mathrm{~N}$ application.

Higher ${ }^{15} \mathrm{~N}$ content was observed in fine roots from the forest floor than in root free litter, but there was no detectable change over time in fine $\operatorname{root}{ }^{15} \mathrm{~N}$ content in the forest floor. The half-life of ${ }^{15} \mathrm{~N}$-tracer in the forest floor was $\approx 103$ weeks compared to the half-life of ${ }^{15} \mathrm{~N}$-tracer in fine roots from surface soil of $\approx 24$ weeks. Retention of ${ }^{15} \mathrm{~N}$-tracer appeared to be greater in the Inceptisols than the Ultisols. We conclude that higher $\mathrm{C} / \mathrm{N}$ ratios may favor $\mathrm{NH}_{4^{-}}{ }^{15} \mathrm{~N}$ immobilization in Inceptisols, and suggest that long-term, atmospheric $\mathrm{N}$ deposition may impact forest floor decomposition.

The vertical $\delta^{13} \mathrm{C}$ profiles of the soils at the four EBIS sites were also evaluated to provide evidence on soil carbon turnover. Vertical profiles of soil $\delta^{13} \mathrm{C}$ are related to $\log \mathrm{C}$ concentration: $\delta^{13} \mathrm{C}=\mathrm{a}+b \cdot \log [\mathrm{C}]$. The regression coefficient ( $b$; slope of the line) represents the per mil enrichment of ${ }^{13} \mathrm{C}$ as one proceeds from an initial substrate (generally the forest floor) to deeper and older $\mathrm{C}$ in the mineral soil. The regression coefficient $(b)$ is also related to forest soil $\mathrm{C}$ partitioning and turnover times along a gradient of altitude and $\mathrm{N}$ availability. Figure 17 shows that this pattern is well represented at the four EBIS sites, and differences in the regression coefficients among sites indicate somewhat longer soil $\mathrm{C}$ turnover times at site $\mathrm{HR}$ than at sites WB, TV, and PR. More negative regression coefficients indicate faster processing 
of fresh soil $\mathrm{C}$ inputs, less new soil $\mathrm{C}$ remaining, and possibly greater stabilization of soil organic matter.
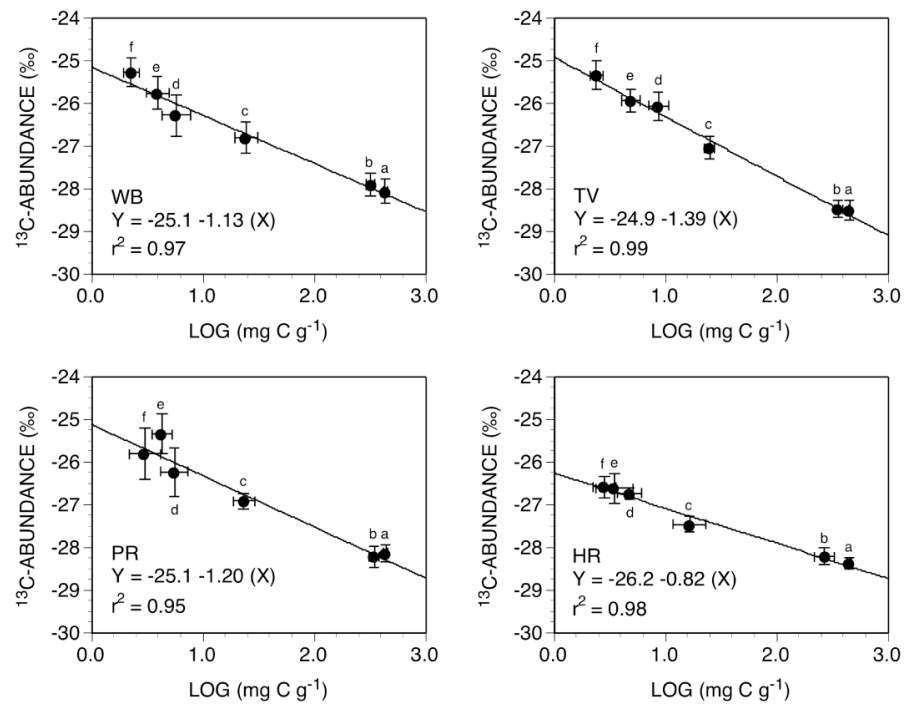

Figure 17. Vertical $\delta^{13} \mathrm{C}$ profiles at the EBIS study sites. Slope (b) is significantly flatter at HR than other sites indicating a longer soil $\mathrm{C}$ turnover time.

\section{Site Vegetation and Litter Production}

Paul J. Hanson and Donald E. Todd

Automated measurements of environmental variables (not shown) and periodic measures of vegetation growth (dbh tape measurements), canopy litter production, and species composition were conducted in conjunction with the EBIS litter manipulations to evaluate the potential influence of site-specific conditions on soil carbon cycling processes. Environmental drivers, such as temperature and soil water status, continue to show no significant differences across sites outside of occasional localized summer precipitation events. There is some potential for species differences (and corresponding changes in litter quality) to impact soil carbon cycling processes across sites (Figure 18), but this does not impact the analysis for years 1 to 3 when constant amounts of litter from the 2000 cohort were added back to the plots. The ambient Pine Ridge litterfall has a greater fraction of red maple litter that may decompose at a faster rate than the mean litter at the other three sites.
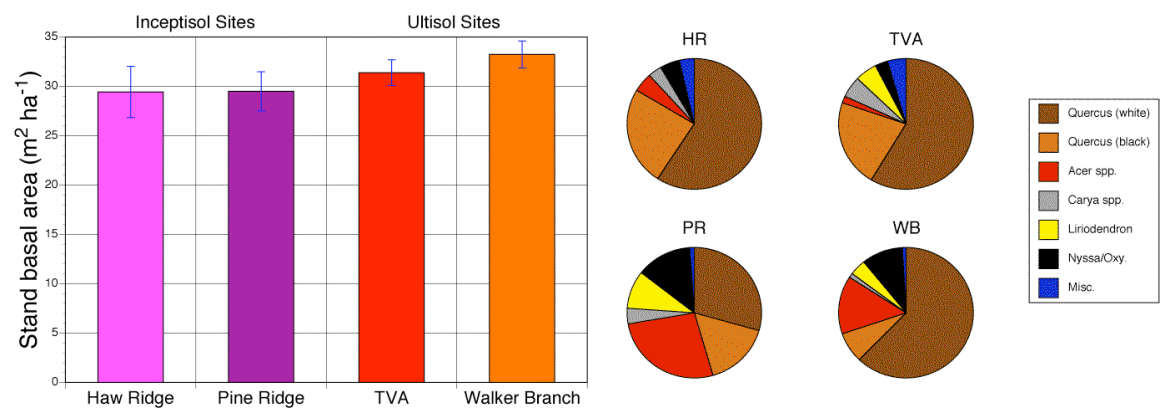

Figure 18. Stand basal area ( \pm se) for the four EBIS sites (left graph), and the species contribution to the basal area at each of the EBIS site (right graph). 
From 2000 through 2005 annual litter production averaged 518 and $475 \mathrm{~g}$ dry matter $\mathrm{m}^{-2}$ for those sites with Ultisol and Inceptisol soils, respectively (Figure 19). These levels closely approximate the experimental additions of $500 \mathrm{~g}$ dry matter $\mathrm{m}^{-2} \mathrm{y}^{-1}$ added to all treatment plots in May 2001, February 2002, and February 2003. Mean basal area growth of live trees (Figure 22) showed annual basal area growth rates between 16 and $27 \mathrm{~cm}^{2} \mathrm{y}^{-1}$ with somewhat higher rates of mean tree growth for TVA and WB.

Air and soil temperatures at the four EBIS sites are not statistically different. Although some variation in mineral soil water status is expected from differences in soil texture at each site. The seasonal patterns of soil water availability and hydrologic flux through all sites is very similar. Litter water content, a highly dynamic but important driver for organic matter decomposition, is also similar at all sites, but isolated summer thunderstorms can generate occasional wet/dry cycles at a single site that may not be represented at all four study sites.
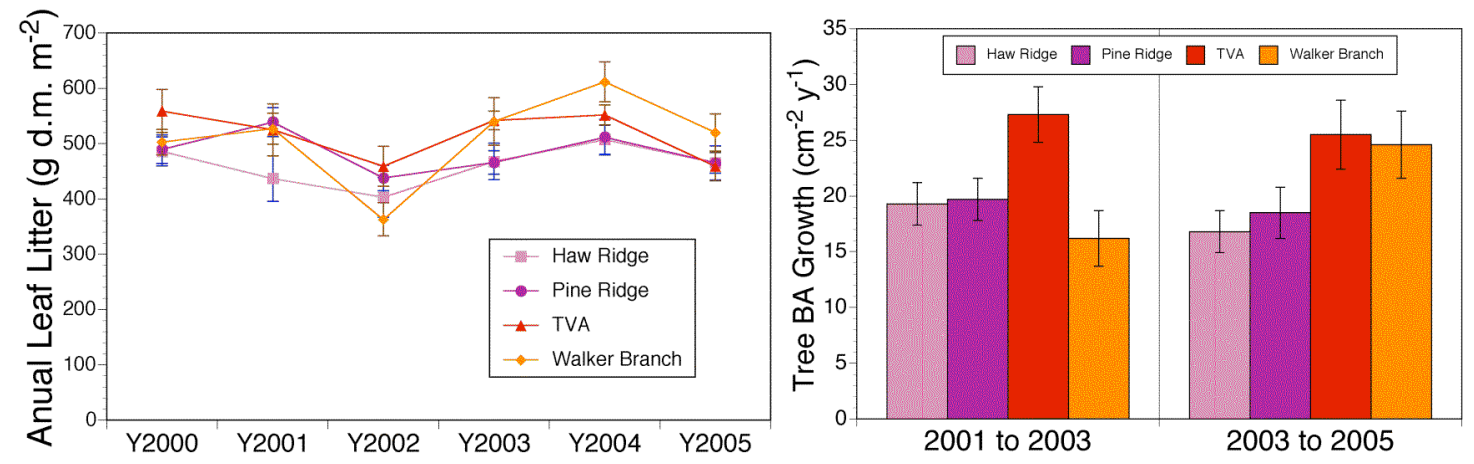

Figure 19. Mean ( \pm se) annual ambient litterfall mass from 2000 to 2005 for each EBIS site (left graph). Mean tree basal area growth for two 2-year periods from 2001 through 2005 (right graph). 


\section{B. New Initiatives}

\section{Mesocosm study of litter to A-horizon DOC transport}

Mats J. Fröberg, Paul J. Hanson, Donald E. Todd, Susan E. Trumbore and others

The goal of this research task is to provide a detailed evaluation of temporal changes in the ${ }^{14} \mathrm{C}$-signature of a single litter cohort as it decomposes and is transported form fresh litter to the A-horizon. These observations will provide evidence for further testing of the cohort-based litter decomposition model (ECHO). Key hypotheses to be tested include:

- Initial (3 to 6 month) mass loss of current year litter cohorts will be predominantly associated with leaching of the labile chemical fraction due to its higher solubility.

- Radiocarbon signatures of heterotrophically respired $\mathrm{C}$ from the Oi-layer is expected to drop dramatically during the first few months due to the loss of soluble materials that are preferentially enriched with ${ }^{14} \mathrm{C}$.

- Leachable DOC from the current litter cohort will be transported to both the Oe/Oa and A horizons where it will represent a measurable fraction of the labile ${ }^{14} \mathrm{C}$ signature at 6 months.

- Because DOC is likely to be a rapidly metabolized carbon source for soil microbes, the presence of DOC-derived ${ }^{14} \mathrm{C}$ in the $\mathrm{Oe} / \mathrm{Oa}$ and $\mathrm{A}$ horizons will be short-lived unless that material is stabilized within protected soil fractions.

We have recently established three different types of $20-\mathrm{cm}$ diameter mesocosms containing: (1) enriched-litterfall at $500 \mathrm{~g} \mathrm{~d} . \mathrm{m} . \mathrm{m}^{-2}(\mathrm{~L})$, (2) enriched-litter plus a $1 \mathrm{~cm}$ Oa layer (LO), and (3) enriched-litter, $1 \mathrm{~cm}$ of Oa and $10 \mathrm{~cm}$ of A horizon (LOA). At the bottom of all mesocosms a layer of glass beads is added to facilitated realistic hydrologic conditions and avoid pooling of water within the measured horizons. Each mesocosm (without the enriched litter) was suspended in sand within plastic buckets (for thermal stability) and was placed in the field in early February 2006, but without the litter added. The enriched litter layer added early in March after all layers have reach field capacity and equilibrated to the forest understory environment. The following diagram and figures show details of the mesocosms design.

Quercus sp. Litter Decomposition Study

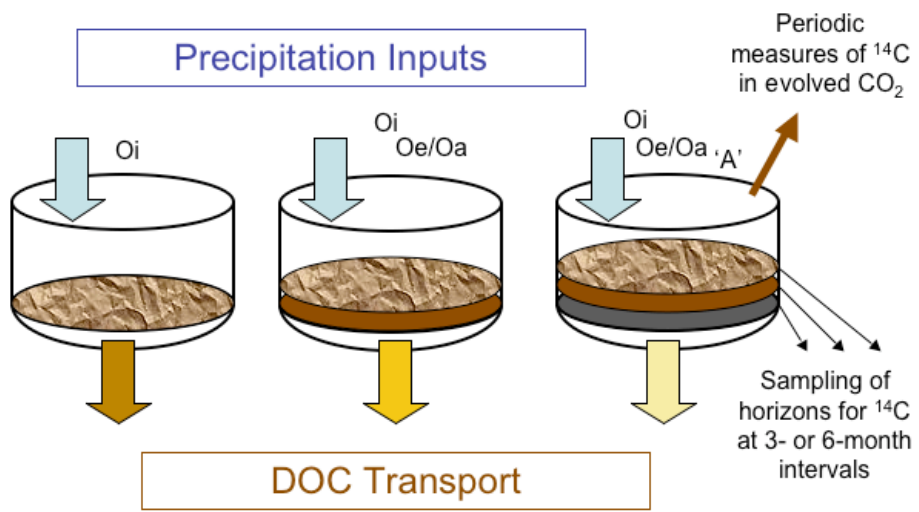

Figure 20. Schematic diagram of one replicate (including 3 mesocosms) of the litter decomposition experiment. The Oi layer will be separated from the underlying Oe/Oa horizon with nylon screen. See also the photographs in Figure 2. 

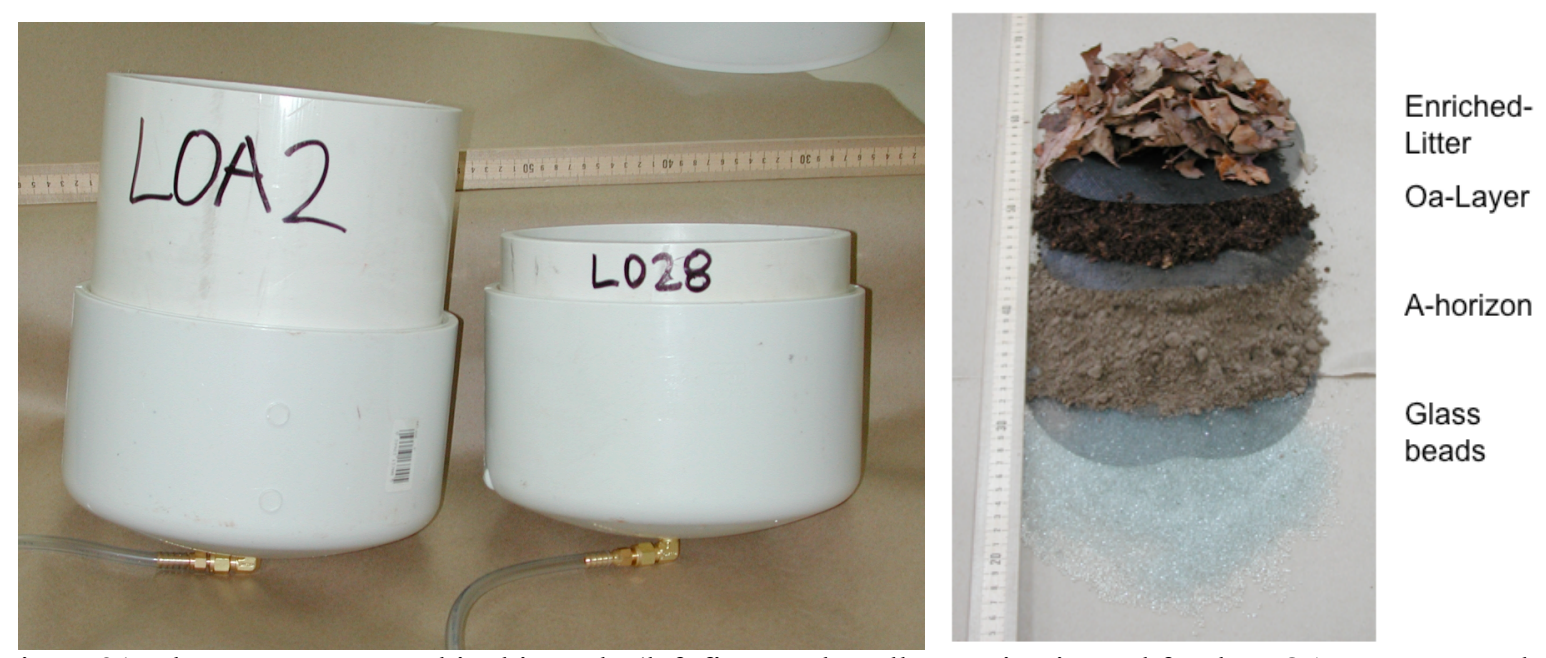

Figure 21. The mesocosms used in this study (left figure. The taller version is used for the LOA treatment and the shorter for the L and LO treatments. Approximate contents of an LOA mesocosm (right graph).

Five replicates of the triple-mesocosm experimental design will be sampled at $0,1,2,4,6$, 8, 12, and 16 months. Every sample of the Oi layer will be analyzed for mass, total C, C chemistry and ${ }^{14} \mathrm{C}$ at each time interval. The $\mathrm{Oe} / \mathrm{Oa}$ and $\mathrm{A}$ layers will be sampled for mass and total $\mathrm{C}$ at all of these intervals, but they will only be sampled for $\mathrm{C}$ chemistry and ${ }^{14} \mathrm{C}$ at 3 -month intervals because of a low anticipated rate of change and to reduce analytical expenses. Assessments of the ${ }^{14} \mathrm{C}-\mathrm{CO}_{2}$-signature evolved from the complete-component mesocosm (combined Oi, Oe/Oa and A layers) will be conducted as point-in-time observations during each sampling interval. DOC leaching from each of the three mesocosm types will be collected periodically as dictated by rain events and pooled for each sampling interval. All solution samples will be kept refrigerated or frozen until the collection period is completed. DOC samples will be analyzed for $\mathrm{C}$ content to estimate DOC loss from a given layer and for ${ }^{14} \mathrm{C}$-signatures of the DOC to estimate the contribution of the enriched litter cohorts to the mobile DOC.

Measurements of soil respiration fluxes and ${ }^{14} \mathrm{C}$ signatures will also be conducted using a combination of autochambers and point-in-time measurements for the purposes of tracking the $\mathrm{C}$ mass balance.

\section{Root turnover and decomposition}

Roser Matamala

The goal of this research task is two-fold: (i) to validate or modify modeled rates of root turnover based on ${ }^{14} \mathrm{C}$ enrichment techniques by means of independent measurements based on conventional root methods and (ii) to measure root derived carbon transfer to soil organic matter (SOM) pools on order to address the relative importance of root litter for SOM accumulation. To achieve these goals, we proposed a field experiment where roots are detached from trees and allowed to decompose in situ. This will allow us to determine the rate of root decomposition independent of the mortality rate of the root population. The research will also allow us to study the transfer of root derived C to SOM pools independently of root population dynamics. Key hypotheses are: 
(1) Root decomposition rates obtained by conventional methods, based on mass and chemistry changes of the root tissues with time, will be use to substantiate predicted root decay rates obtained by modeling of the depletion of enriched ${ }^{14} \mathrm{C}$ roots at the EBIS sites.

(2) Root production and mortality rates estimated using conventional methods, such as changes in live versus dead root mass with time, are predicted to be similar to modeled rates obtained by the ${ }^{14} \mathrm{C}$ technique used by EBIS investigators.

(3) Major differences between conventional and ${ }^{14} \mathrm{C}$ techniques will be due to the finer scale, root traits and tissue chemistry, used with conventional methods.

(4) An increase in root litter will translate to an increase in microaggregated soil $\mathrm{C}$ more than through non-aggregated silt and clay. A large (as much as $600 \mathrm{~g} \mathrm{dw} / \mathrm{m}^{2}$ ) and labeled root material will be follow into SOM fractions.

Methods: We will take advantage of the new ${ }^{14} \mathrm{C}$-enrichment that occurred in the summer of 2005 at TVA and PR sites to address these hypothesis, quantify the rate of root decomposition and the effect of increased root inputs on the transfer rate of root derived $\mathrm{C}$ to SOM pools. Three plots, each $2 \mathrm{~m} \times 3 \mathrm{~m}$, will be established outside the current EBIS experimental TVA plots. Intact soil cores, $15 \mathrm{~cm}$ deep by $5.3 \mathrm{~cm}$ in diameter will be collected in clear plastic tubes, the ends of the tubes will be fitted with a $160-\mu \mathrm{m}$ polyethylene mesh caps, soaked to field capacity, and reinserted at random (not in their original places) into the ground in their original orientation and covered with an organic layer. At the beginning of the study and then every four months for a period of two years (or until the decomposition curve is well defined for each root type) a number of intact soil cores will be taken from each plot. The number of intact soil cores taken at each sampling time will depend on the variability of root mass in the field (Dornbush et al., 2002). This variability is now being determined for TVA and PR sites on 25 cores sampled last summer. At each sampling time, all cores will be processed as specified by Dornbush et al., 2002, expect for a subsample of soil that will be kept for soil analysis. Soils will be fractionated according to methods currently employed by J. Jastrow and analyzed for total $\mathrm{C}$ and ${ }^{14} \mathrm{C}$ at the initial and end of the year harvests.

Initially, roots will be separated into three diameter size groups: (1) diameter $<0.5 \mathrm{~mm}$, (2) diameter $0.5-2 \mathrm{~mm}$ and (3) diameter $>2 \mathrm{~mm}$. Root separations will be re-evaluate at the first sampling to verify appropriate separation of different type roots as indicated by their chemistry, $\mathrm{N}, \mathrm{Ca}, \mathrm{C} / \mathrm{N}$ and lignin contents. The sampling of intact cores over time will allow us to estimate root decomposition of the root population and to distinguish decomposition dynamics between root types. Carbon-14 measurements will be made for each group at every harvest and ${ }^{14} \mathrm{C}$ dilution will be modeled to estimate root decomposition by this method. 


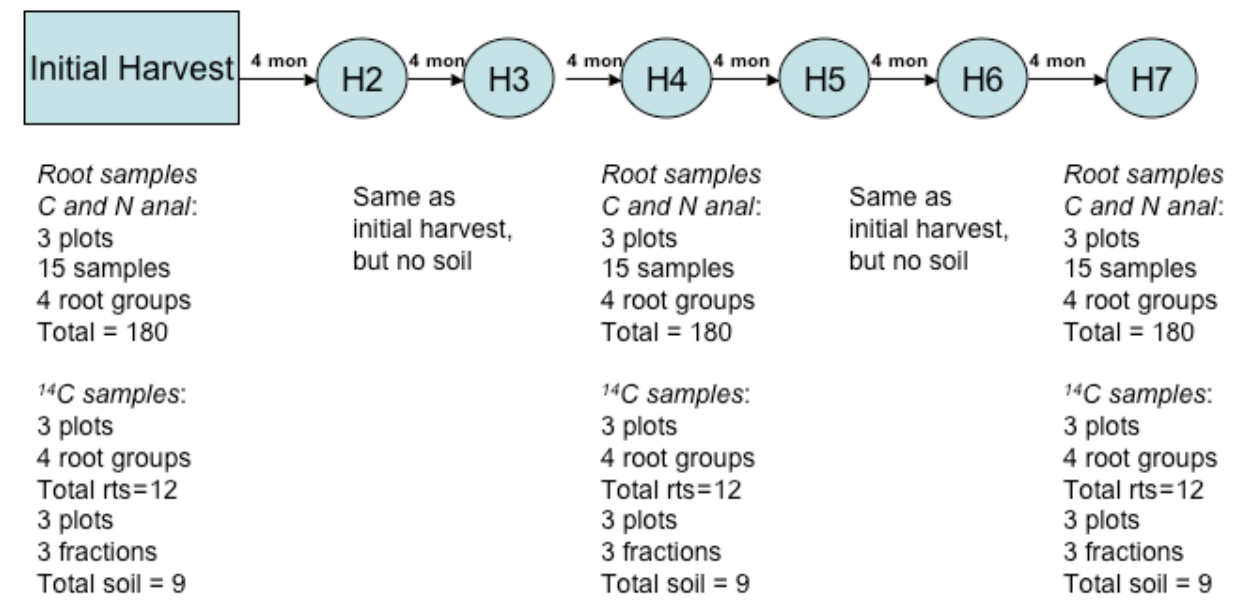

Figure 22. Scheme of sampling and sample analysis for 1) Root decomposition and 2) Increased root litter input studies. Total C\&N analyses $=1260$ and total ${ }^{14} \mathrm{C}$ analysis $=111$ over three years.

\section{Compound specific radiocarbon values on phospholipid fatty acids Christiane Kramer and Susan Trumbore}

As a new effort, we will measure the radiocarbon signature of specific phospholipid fatty acids (PLFA) and other lipid biomarkers in archived EBIS soils and the time series of $\mathrm{O}$ and $\mathrm{A}$ horizons in the mesocosm experiments. Our overall goals are to define what portion of the microbial community relies on root or leaf litter versus older organic matter substrates and how the isotopic signatures of the most abundant PLFAs compare to the bulk value of heterotrophically respired $\mathrm{CO}_{2}$. This initiative will apply a new technique (compound specific radiocarbon) in combination with the time series of incorporation of an isotope tracer to give unique insights into the dynamics of carbon substrates that are fuelling the soil microbial community.

Compound specific isotope measurements of microbial biomarkers confirm that microbes (which 'are what they eat $+/-1 \%$ ' isotopically) utilize a range of $\mathrm{C}$ substrates - from recent photosynthetic products to substrates that are at least decades old. Phospholipid fatty acids (PLFAs), which are found in cell membranes and may have structures specific to classes of bacteria, fungi or plants, are used to provide a 'fingerprint' of microbial community structure. 


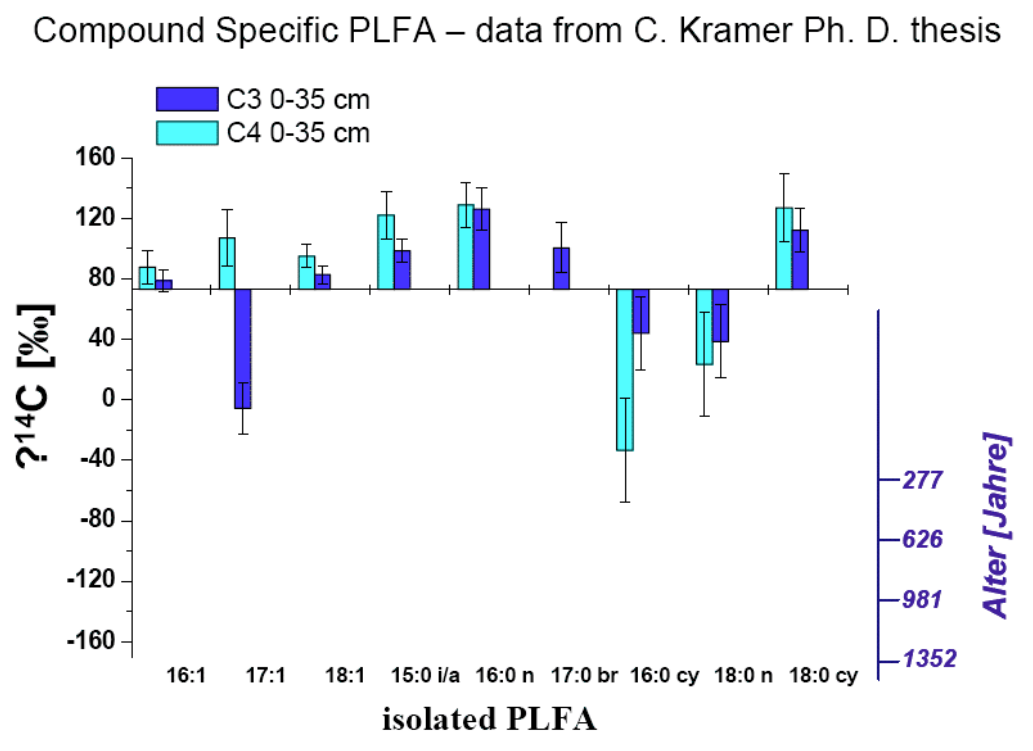

Figure 23. Radiocarbon signatures of isolated phospholipid fatty acid compounds from two agricultural soils in Germany (one planted with C3 and the other with C4 vegetation).

In Figure 23, each compound represents a different type of structure in the microbial cell walls; for example 15:0 $\mathrm{i} / \mathrm{a}$ is a structure indicative of gram-positive bacteria. The $\mathrm{X}$-axis is placed at the ${ }^{14} \mathrm{C}$-signature expected for $\mathrm{C}$ derived from recent photosynthetic products; values above the line therefore represent $\mathrm{C}$ substrates up to decades old, while those below the axis have a significant component of pre-bomb ${ }^{14} \mathrm{C}$. The data show a large range of variation in $\mathrm{C}$ sources for the microbes in this soil, although the compounds isolated are not unique to one specific microbe. At UCI, we will be able to analyze samples as small as 5-10 micrograms of C (as opposed to the 100 micrograms of $\mathrm{C}$ required for the analyses in the Figure), hence we can concentrate on compounds that are more specific to a given type of microbe.

By looking at the microbial community itself through PLFA analyses, and thus avoiding dilution of ${ }^{14} \mathrm{C}$ signals by a large background, we will perhaps be able to see the utilization of DOC-derived $\mathrm{C}$ substrates in the mineral soil. These analyses should help us distinguish between sources of C (root exudates, leaf litter, older SOM) for different types of bacteria and fungi. The use of compound specific PLFA is still relatively new, and EBIS samples present a tremendous opportunity to observe the dynamics of $\mathrm{C}$ flow through the microbial pool.

We will analyze PLFAs in two types of samples: (1) archived frozen samples from the 2004 sampling (for comparison with other ${ }^{14} \mathrm{C}$ measures in organic matter fractions), with the goal of measuring the change in ${ }^{14} \mathrm{C}$ abundance for compounds specific to living fungi and bacteria to determine how substrates vary with soil depth; and (2) we will sample a time series of ${ }^{14} \mathrm{C}$ in PLFA extracted from $\mathrm{Oe} / \mathrm{Oa}$ and $\mathrm{A}$ horizons in the mesocosm study - to distinguish how rapidly the ${ }^{14} \mathrm{C}$-labeled litter enters the microbial community and which organisms are metabolizing it. We will compare the PLFA analyses to incubations; samples will be taken when the mesocosms are harvested. 


\section{Integration: Modeling and Mass Balance of the Soil C Cycle}

Modeling in EBIS has two main purposes. One is tactical and targeted to achieve proximate objectives. These include organizing data into logical constructs consistent with measurements observations. Such data analysis models are being developed within tasks of the EBIS project to investigate specific components of ${ }^{14} \mathrm{C}$ data such as: What is the potential impact of differential leaching or decomposition of materials on ${ }^{14} \mathrm{C}$ distribution in litter cohorts? How can root carbon pools and turnover rates be reconciled with observed ${ }^{14} \mathrm{C}$ data? Can the carbon budget be closed with current measurements? In addition to these tactical modeling objectives, a second goal of EBIS is to apply what is learned about carbon cycling, particularly decomposition dynamics, to a more general description of ecosystem $\mathrm{C}$ dynamics. With such a description the experimental results from the EBIS project can be generalize for other ecosystems. Targeted activities are described below in the context of the ECHO and Radix models and testing of more general models are described for Daycent, Roth-C and DyDOC. We also provide a summary of the soil $\mathrm{C}$ cycle mass balance for the EBIS plot soils.

\section{Enriched Litter Cohort Model (ECHO)}

Paul J. Hanson, Charles T. Garten, W. Mac Post, Chris Swanston and Sue Trumbore

The unexplained patterns of Oi-layer ${ }^{14} \mathrm{C}$ accumulation over time and the presence of differential ${ }^{14} \mathrm{C}$-signatures between decomposing litter cohorts and DOC leaching suggested that a cohort specific model of Oi-layer $\mathrm{C}$ and ${ }^{14} \mathrm{C}$ cycling was needed to capture carbon movements and intra-annual decomposition patterns driven by weather variation from year-to-year. Such a model was developed using STELLA ${ }^{\circledR}$ Version 8.1 ((Figure 24). The model allows for multiple cohorts of Oi (i.e., recognizable litter) and a single layer of Oe/Oa (i.e., humus). Litter decomposition is simulated using laboratory-based relationships driven by daily temperature and litter and soil water potential values (Hanson et al. 2003). Litter leaching from all Oi-layer cohorts was allowed to take place when throughfall events forced vertical hydrologic movement leading to annual $\mathrm{C}$ transfers of approximately $60 \mathrm{gC} \mathrm{m}-2 \mathrm{y}-1$ from all Oi- layer cohorts (the threshold was set based on observations of Anderson 1973).

\section{Enriched Litter Cohort Model (ECHO)}

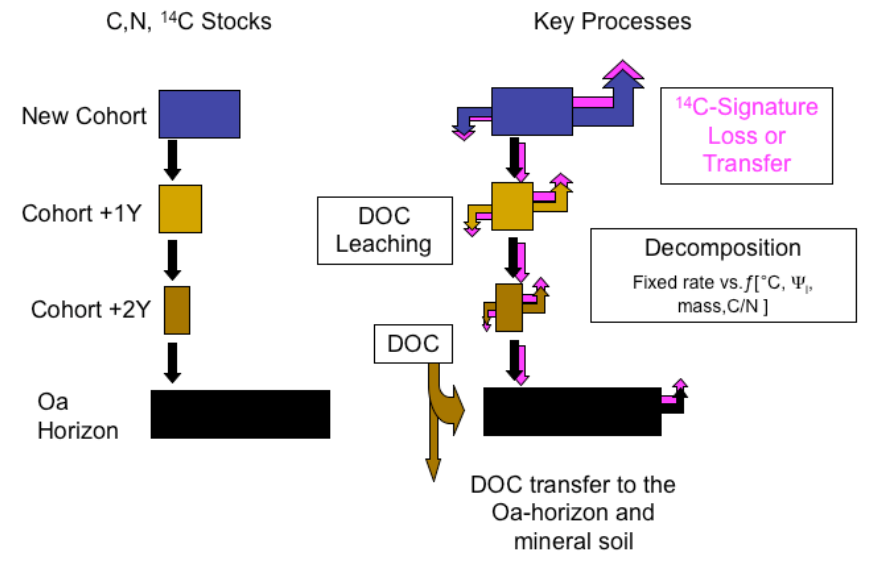

Figure 24. Component of a multi-cohort litter decomposition model structured to handle

$$
\mathrm{C} \text { and }{ }^{14} \mathrm{C} \text { cycling. }
$$




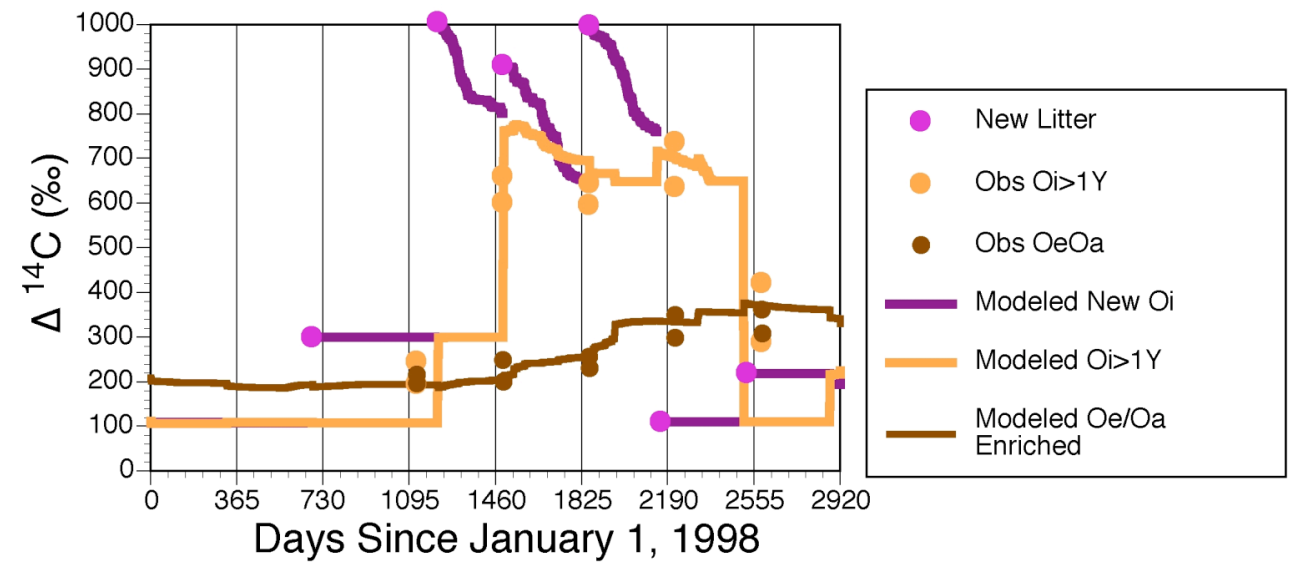

Figure 25. ECHO model observed vs. simulated Oi- and Oe/Oa-layer ${ }^{14} \mathrm{C}$-signatures for an eastern site receiving enriched litter in 2001, 2002, and 2003.

The model is capable of handling multi-year decomposition of litter layer cohorts consistent with observed litter mass loss for Walker Branch Watershed (Figure 25). When the model was run with fixed litter cohort turnover times and no DOC leaching of $\mathrm{C}$ or ${ }^{14} \mathrm{C}$ it failed to capture the observed patterns of ${ }^{14} \mathrm{C}$ in the $\mathrm{Oi}>1 \mathrm{Y}$-layer. Substantial improvement was obtained by including (1) soil temperature and water dependent decomposition functions, (2) DOC leaching of $\mathrm{C}$, and (3) the observed differential patterns of ${ }^{14} \mathrm{C}$-signatures between leachable $\mathrm{C}$ and bulk litter into the model.
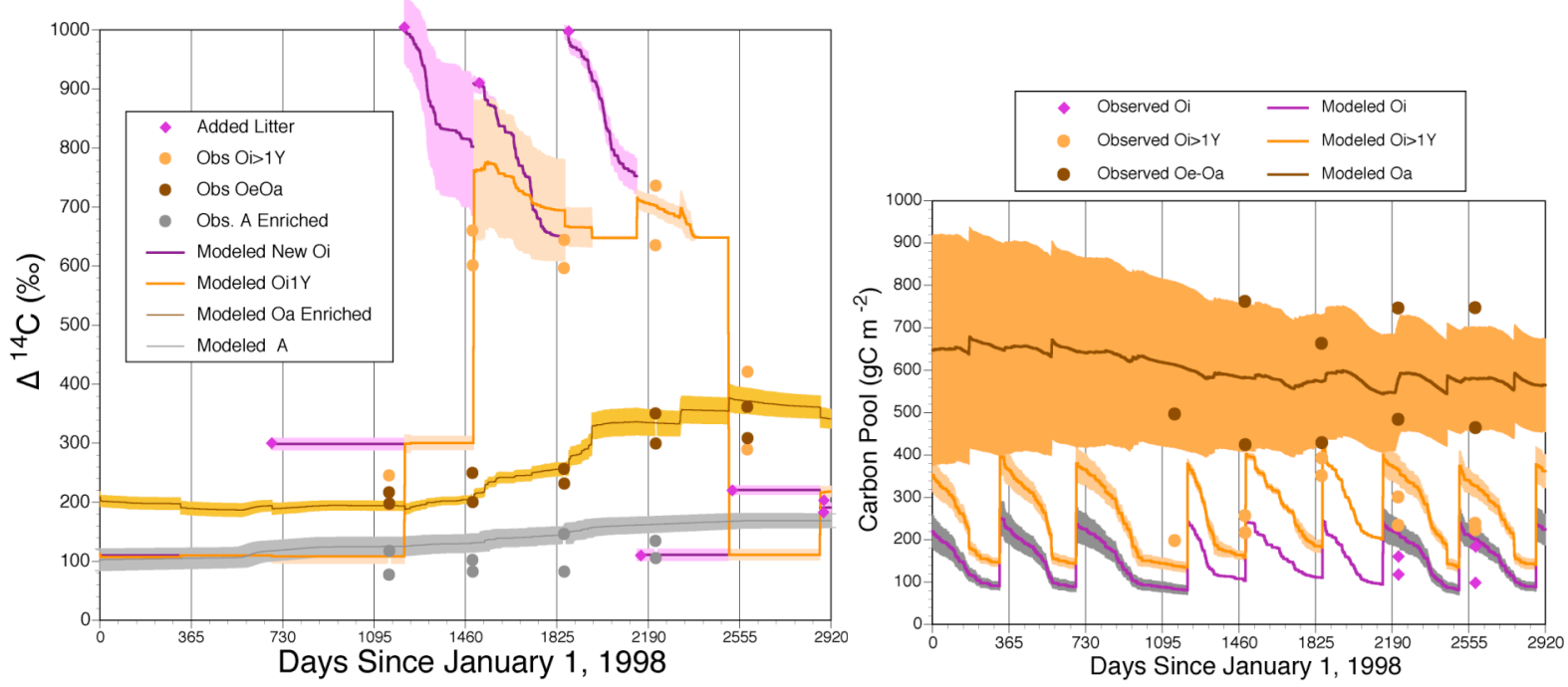

Figure 26. Probabilistic ECHO model predictions contrasting simulated Oi, Oe/Oa, and A-horizon ${ }^{14} \mathrm{C}$ (left) or C pool values (right) with observations for an eastern site receiving enriched litter in 2001, 2002, and 2003.

The ECHO model has also been run in a probabilistic mode (Figure 26) showing the conservative nature of the model simulations. Substantial variability can be, but isn't necessarily predicted for ${ }^{14} \mathrm{C}$ values. The extent of variation stems from the number of annual leaf cohorts 
contributing to the Oi-layer or the cumulative nature of ${ }^{14} \mathrm{C}$ additions to the Oe/Oa-layer and the A-horizon. The models ability to reproduce measured $\mathrm{C}$ pools is also demonstrated, but this is an area for improvement. Decreasing variation in the predicted Oe/Oa carbon pool over the 8-year simulation suggests that the initial starting values for the humus layer may not have been at equilibrium with the local climatological conditions.

The availability of a verified cohort model, like ECHO allows it to be used to address mechanistic questions regarding soil carbon cycling processes and drivers in the context of a sensitivity analysis. Two examples of are shown in Figure 27. The first graphic reveals the sensitivity of predicted $\Delta^{14} \mathrm{C}$ values to the assumption of how much leachable DOC leaving fresh leaf litter is retained in the humus layer, and the second shows that critical litter CN values for distinguishing the transfer of litter from recognizable to humus pools is also an important variable for further study.
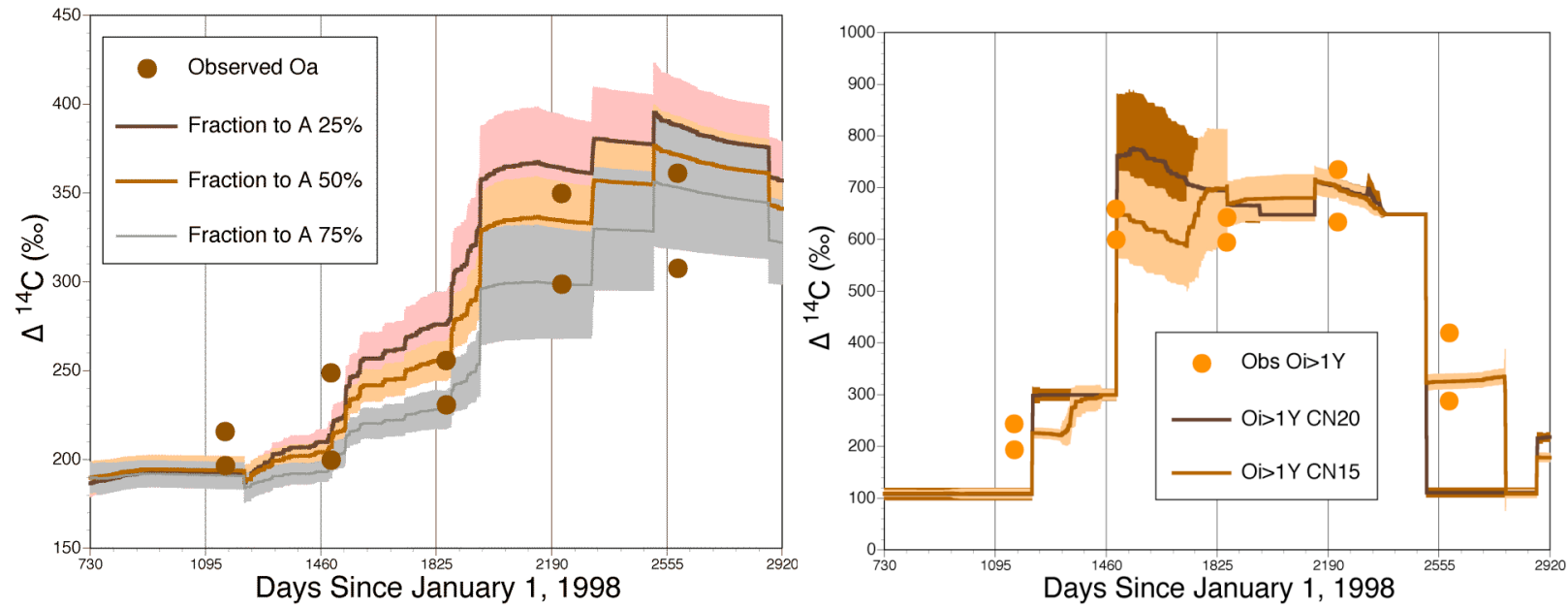

Figure 27. Sensitivity analysis of the effect of DOC retention on measured humus layer ${ }^{14} \mathrm{C}$ (left graph) or the influence of critical $\mathrm{CN}$ rations for the litter to humus transition (right graph).

Models like ECHO that address multiple-cohorts and include realistic representations of decomposition and leaching processes (driven by intra-annual temperature and litter and soil water conditions) are needed to successfully capture organic layer $\mathrm{C}$ cycling and $\mathrm{C}$ transfer to the mineral soil.

References:

Hanson PJ, O’Neill EG, Chambers MLS, Riggs JS, Joslin JD, Wolfe MH (2003) Soil respiration and litter decomposition. In: Hanson PJ, Wullschleger SD, Eds, North American Temperate Deciduous Forest Responses to Changing Precipitation Regimes. Springer, New York, pp. 163-189.

Andersen JM (1973) The breakdown and decomposition of sweet chestnut (Castanea sativa Mill.) and beech (Fagus sylvatica L.) leaf litter in two deciduous woodland soils. I. Breakdown, leaching and decomposition. Oecologia 12:251-274. 


\section{Fine Root Turnover Modeling}

William Riley, Margaret S. Torn, Julia B. Gaudinski, and J. Dev Joslin

Root mortality turnover times in temperate forests have been estimated by several methods, including mini-rhizotron observations, sequential coring, and isotopic analysis. These methods yield very different estimates of mortality turnover times. Some of the differences undoubtedly reflect the fact that different methods tend to preferentially observe some root pool dynamics better than others. Nevertheless, a significant amount of the discrepancy stems from limitations in the models used to translate the empirical observations to root mortality turnover times. The EBIS data sets provide an opportunity to develop and test a more general model of root population dynamics. For example, root screens installed in the soil for fixed periods of time can be used to characterize the ${ }^{14} \mathrm{C}$ content of new root growth, and thus constrain estimates of the use of stored $\mathrm{C}$ reserves in root growth.

With the unique isotopic labeling of an intact, mature forest, the EBIS experiment has provided new and valuable insights into the processes of fine root production, mortality, and decomposition. We have used the EBIS observations of root ${ }^{14} \mathrm{C}$ content over time to develop and parameterize a dynamic root model (Figure 28) that can quantify the (a) use of stored C reserves for new root growth; (b) mortality turnover times of multiple live root pools and decomposition turnover times of multiple dead root pools; (c) $\mathrm{C}$ fluxes from living to dead root pools; and (d) C fluxes out of the dead pool via decomposition.

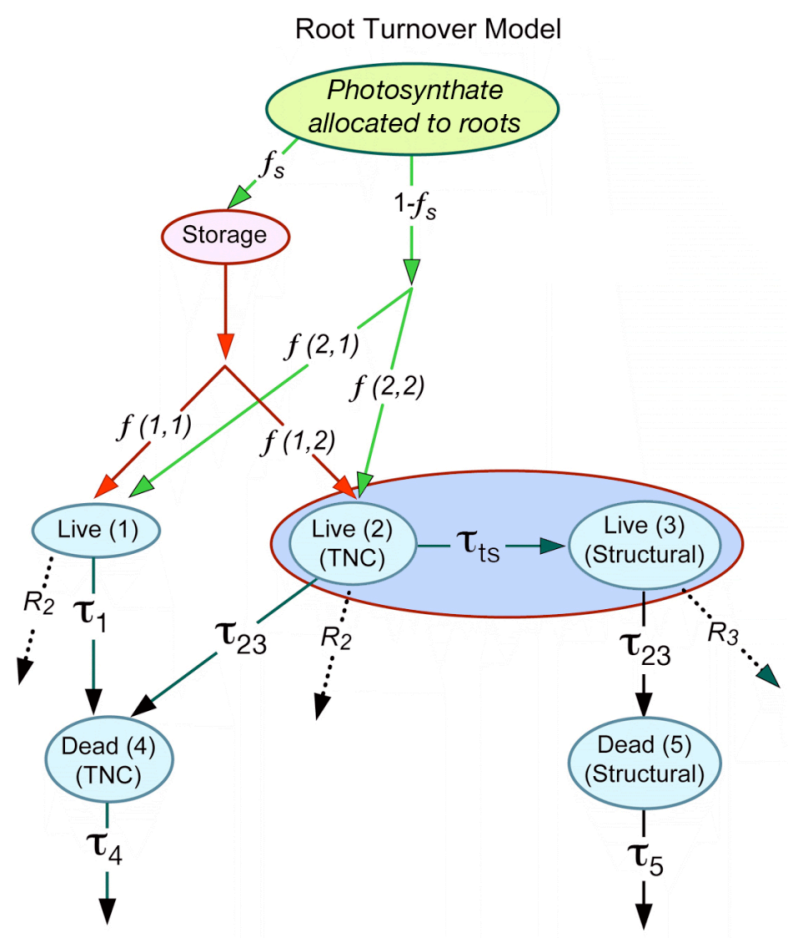

Figure 28. Schematic of Root Model. TNC = total non-structural carbon.

A central feature of the root model is the inclusion of two live root pools; one that turns over rapidly (on the order of months) and one that consists of longer-lived roots ( $>5$ years in age). The delineation of these two pools explains the relatively rapid enrichment of live roots 
only one year after the release (caused by turnover of the short-lived roots), and the relatively slow decline of the enrichment in the subsequent years (caused by persistence of the long-lived roots). To represent the complexity in root dynamics while minimizing the number of unknown parameters, the model is designed with the following attributes:

- Root ages that are non-normally distributed,

- Representation of fine roots as two pools, each with structural and non-structural C,

- $\quad$ Stored $\mathrm{C} /{ }^{14} \mathrm{C}$,

- Seasonal growth and respiration patterns,

- Monte Carlo analysis of uncertainty, and

- A $X^{2}$ approach to find best-fit parameters to match root $\mathrm{C}$ and $\Delta^{14} \mathrm{C}$ data.

To apply the model we also had to develop an estimate of atmospheric $\Delta^{14} \mathrm{C}$ values over time. Unfortunately, direct measurements of atmospheric $\Delta^{14} \mathrm{C}$ were unavailable during the 1999 pulse (and possible West ORR pulse in 2000), so we used a combination of $\Delta^{14} \mathrm{C}$ measurements in tree cores, soil gas, leaves, and soil respiration to construct a consistent atmospheric history that will also be valuable to other investigators in the EBIS project.

To date, we have applied the model to (1) estimate the mortality turnover time in the fast live root pool and fraction of BGPP being stored and (2) estimate mortality turnover times for the longer-lived fine roots and decomposition turnover times in the dead root pools. First, using Monte Carlo error propagation, the best-fit $X^{2}$ approach, and the root screen data, we estimate that $5 \%$ of BGPP is being stored over the course of the year and that the flux-weighted $\mathrm{C}$ turnover time in the storage pool is about $0.7 \mathrm{y}$ (Figure 29). Notably, this turnover time is about half what would be calculated from a simple exponential curve fit to the root screen measurements.

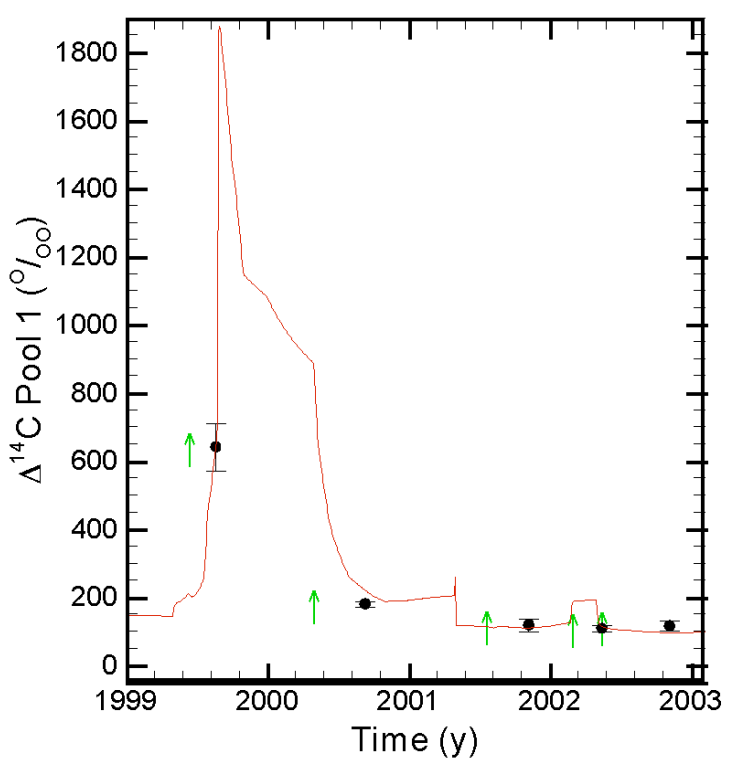

Figure 29. Best-fit model results of root screens. The green arrows indicate implantation of the root screens and the data points indicate when each core was removed. The best-fit parameters for this simulation are $f_{s}=0.05$ and $\tau_{s n}=0.7 \mathrm{y}$.

Second we have used the model and root core data to improve estimates of the slower fine root pool mortality turnover times in the $0-15 \mathrm{~cm}$ depth interval and $<0.5 \mathrm{~mm}$ root class (Figure 30). In these simulations, the predicted best-fit turnover time of the live root pools was 6 
months and 5 years; and of dead root pools was 1.9 and 5.4 years. The best-fit turnover times were estimated from a combination of east and west side ${ }^{14} \mathrm{C}$ and biomass data.

One of the key goals of the EBIS experimental design is to compare the fate of plant $\mathrm{C}$ that is input to the soil as leaf litter versus root tissues. Preliminary model predictions of the $C$ fluxes out of the fast cycling and long-lived non-structural pools and out of the dead root pools are shown in Table 1.

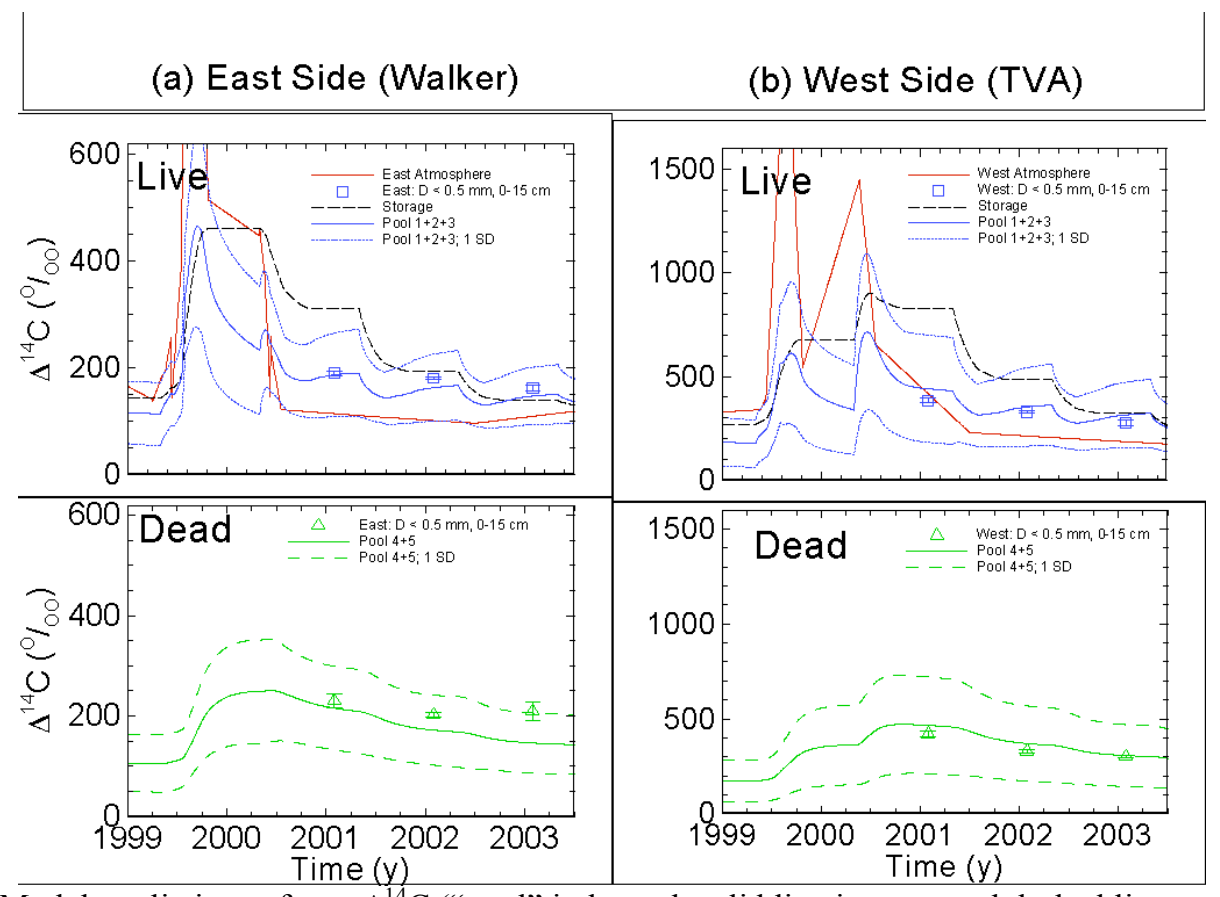

Figure 30. Model predictions of root $\Delta^{14} \mathrm{C}$ ("pool" in legend; solid line is mean and dashed lines are $\pm 1 \mathrm{SD}$ for a Monte Carlo analysis of estimated variability in parameters) and empirical root core ${ }^{14} \mathrm{C}$ data, for $<0.5 \mathrm{~mm}$ root class, $0-15 \mathrm{~cm}$ depth. The upper-panel shows live roots. The lower-panel shows dead roots.

Table 1. Preliminary prediction of $\Delta^{14} \mathrm{C}$ flux to soil from root death or decay, for very fine roots $(\leq 0.5$ $\mathrm{mm})$ in the A horizon $(0-15 \mathrm{~cm})$. Because that depth/size category represents about one-quarter of total fine roots (Fig 2B-1), we estimate a flux from dead roots of roughly $100 \mathrm{~g} \mathrm{~m}^{2} \mathrm{y}^{-1}$ for the total profile. The $\mathrm{C}$ fluxes are yearly integrals of daily predictions. Non-structural $\mathrm{C}$ is the net $\mathrm{C}$ flux from the live nonstructural pool to the labile dead root pool. The dead roots column shows the net $\mathrm{C}$ leaving the dead root pool and entering SOM.

\begin{tabular}{|c|c|c|c|c|}
\hline \multirow[t]{2}{*}{ Year } & \multicolumn{2}{|c|}{$\frac{\text { Non-Structural C }}{<0.5 \mathrm{~mm}, A \text { horizon }}$} & \multicolumn{2}{|c|}{$\begin{array}{c}\text { Dead Roots } \\
\leq 0.5 \mathrm{~mm}, \text { A horizon }\end{array}$} \\
\hline & $\Delta^{14} \mathrm{C}(\% 0)$ & Flux $\left(\mathrm{g} \mathrm{m}^{-2} \mathrm{y}^{-1}\right)$ & $\Delta^{14} \mathrm{C}(\%)$ & Flux $\left(\mathrm{g} \mathrm{m}^{-2} \mathrm{y}^{-1}\right)$ \\
\hline 1999 & 464 & & 395 & \\
\hline 2000 & 329 & & 416 & \\
\hline 2001 & 145 & & 314 & \\
\hline 2002 & 117 & & 269 & \\
\hline 2003 & 125 & & 247 & \\
\hline Average & & 21.2 & & 25.2 \\
\hline
\end{tabular}




\section{Carbon-Cycle Modeling: Daycent \\ William J. Parton}

The Century EBIS project objectives included: 1) setting up the Daycent model to simulate the ecosystem dynamics of the deciduous forest at Oak Ridge, Tennessee and the EBIS $\Delta^{14} \mathrm{C}$ experiment, and 2) modification of Daycent model so that it correctly represents the observed patterns of labeled $\Delta^{14} \mathrm{C}$ litter added during the EBIS experiment. The model used the observed soil properties, daily weather and atmospheric $\Delta^{14} \mathrm{C}$ data from the Oak Ridge site to run the Daycent model for the EBIS ${ }^{14} \mathrm{C}$ litter manipulation experiment. The daily weather data (daily maximum and minimum air temperature and precipitation) from the last 105 years was used to drive the model along with the observed atmospheric $\Delta^{14} \mathrm{C}$ content for the east and west sites. Observed $\Delta^{14} \mathrm{C}$ is based on tree ring analysis during the last 55 years and atmospheric $\Delta^{14} \mathrm{C}$ and tissue $\Delta^{14} \mathrm{C}$ measurements from 2000 to 2005 at the east and west EBIS experimental sites.

The first step in Century EBIS project was to adjust the Daycent model so that it could correctly represent the observed pattern of plant production at the Oak Ridge site from 19912000 (Hanson and Wullschleger 2003). Hanson's data set included information about plant production and carbon levels for the major plant components (e.g., leaves, fine roots, coarse roots, fine branches, and large wood) from 1991 to 2000 . The major changes to the Daycent model needed to better represent the observed plant production data included increasing the maximum leaf area index to 6 , reducing the carbon allocation to fine roots (fraction allocated to fine roots ranges from $20 \%$ to $30 \%$ depending on soil fertility and soil water status), and changing the relative amount of carbon allocated to large wood, coarse roots, and fine branches. The model was also adjusted so that it could correctly represent the EBIS ${ }^{14} \mathrm{C}$ litter addition experiments that started in year 2000. The major model output variables considered included the $\Delta^{14} \mathrm{C}$ content of the relatively undecomposed surface litter (Oi) layer, the well decomposed

\section{EBIS Daycent C Pools}

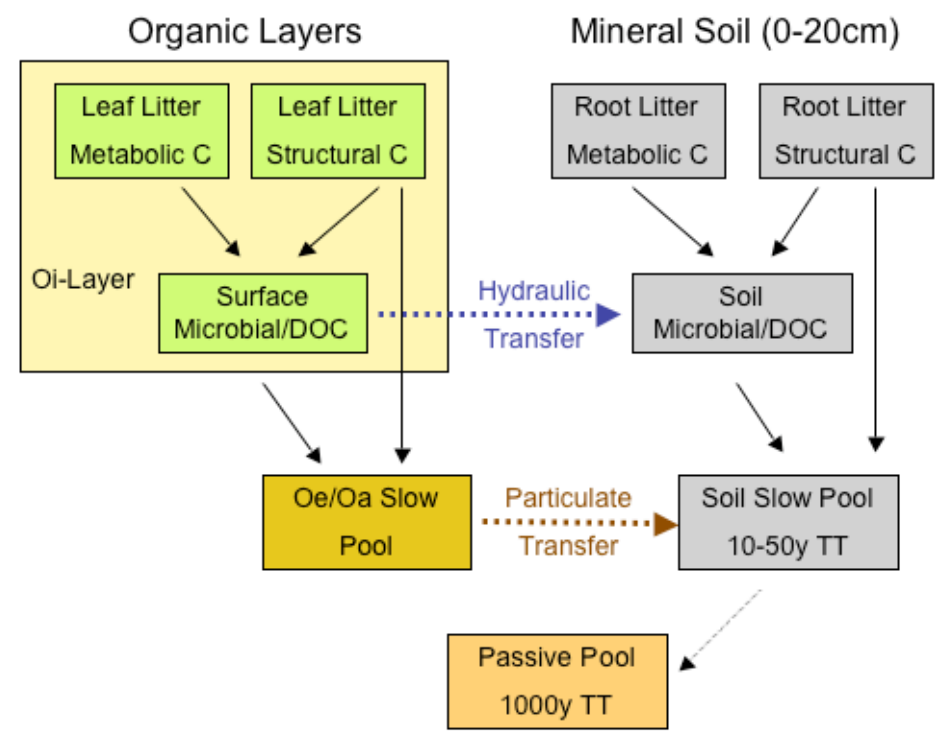

Figure 31. Revised structure of EBIS Daycent showing correspondence to the measured pools of $\mathrm{C}$ and ${ }^{14} \mathrm{C}$. 
surface material (Oe/Oa layer), and the mineral soil layer over 0-20 cm (A horizon). A major change to the Daycent model was to separate the original slow organic matter (SOM) pool in Century into a surface slow pool and mineral soil slow pool (Figure 31). The surface slow pool corresponds to the Oe/Oa surface litter pool. As part of this change, we added a flow that simulates the physical mixing of Oe/Oa layer into the soil mineral slow pool (0 to $20 \mathrm{~cm}$ soil depth). Some of the other model changes include adjusting the values of the turnover times for the soil mineral slow pool, Oe/Oa layer, and passive soil pool. We also adjusted the assumed atmospheric $\Delta^{14} \mathrm{C}$ content prior to 1900 to a value, which would result in a $\Delta^{14} \mathrm{C}$ value for the passive SOM pool in 1995 which equaled the $\Delta^{14} \mathrm{C}$ value of the SOM in the $30-45 \mathrm{~cm}$ soil layer $\left(\Delta^{14} \mathrm{C}\right.$ is $\left.\sim 50\right)$. This is based on the assumption the $\Delta^{14} \mathrm{C}$ content of the passive SOM would not have changed much during the last 100 years (assumed model turnover rate of $>1000$ years), and that the $\Delta^{14} \mathrm{C}$ content of the $30-45 \mathrm{~cm}$ layer is close to the value of the $\Delta^{14} \mathrm{C}$ content of the $0-20$ $\mathrm{cm}$ passive pool at the beginning of the experiment.

\section{Daycent Model results}

Table 2 shows a comparison of the observed and simulated mean plant production for the different plant parts from 1990 to 2000 . Maximum and minimum yearly plant production during

Table 2. Comparison of observed and simulated mean plant production $\left(\mathrm{gC} \mathrm{m}^{-2} \mathrm{y}^{-1}\right)$ and ecosystem $\mathrm{C}$ level $\left(\mathrm{gC} \mathrm{m}^{-2}\right)$ for the Oak Ridge site. Simulated and observed maximum and minimum values of plant production from the 1991-2000 time period are shown in parentheses.

\begin{tabular}{|c|c|c|}
\hline Plant Production & $\begin{array}{c}\text { Simulated } \\
\left(\mathrm{g} \mathrm{C} \mathrm{m}^{-2} \mathrm{y}^{-1}\right)\end{array}$ & $\begin{array}{c}\text { Observed } \\
\left(\mathrm{g} \mathrm{C} \mathrm{m}^{-2} \mathrm{y}^{-1}\right)\end{array}$ \\
\hline Leaf & $211(210-214)$ & $240(230-257)$ \\
\hline Fine Roots & $135(50-264)$ & $153(120-207)$ \\
\hline Branch & $54(13-117)$ & $60(40-95)$ \\
\hline Large Wood & $180(45-386)$ & $150(118-240)$ \\
\hline Coarse Roots & $11(3-23)$ & $12(6-22)$ \\
\hline Total Production & $593(323-1003)$ & $650(550-720)$ \\
\hline Ecosystem C Level & $\begin{array}{c}\text { Simulated } \\
\left(\mathrm{g} \mathrm{C} \mathrm{m}^{-2}\right)\end{array}$ & $\begin{array}{c}\text { Observed } \\
\left(\mathrm{g} \mathrm{C} \mathrm{m}^{-2}\right)\end{array}$ \\
\hline Large Wood & 10600 & 6000 \\
\hline Branch & 910 & 1600 \\
\hline Fine Roots & 250 & 360 \\
\hline Coarse Roots & 630 & 940 \\
\hline Oi & 310 & 280 \\
\hline $\mathrm{Oe} / \mathrm{Oa}$ & 640 & 570 \\
\hline Total Soil C $(0-20 \mathrm{~cm})$ & 4000 & 4100 \\
\hline
\end{tabular}

the 10-year period are also presented in Table 2 . The model results compare favorably with the observed mean plant production data. The main difference is that leaf and total plant production are slightly underestimated (most of the underestimation in the total production comes from lower leaf production). Both the model and the data show that leaf production doesn't vary much between years, while observed data and model results show that the other plant parts have substantial yearly variations in plant production. The model results seem to have higher year-toyear variations in plant production compared to the observed data for fine roots and the live wood components. Table 2 also shows a comparison of the observed vs. simulated carbon levels 
for large wood, branches, fine roots, coarse roots, Oi surface layer, Oe/Oa surface layer, and total mineral soil carbon in the $0-20 \mathrm{~cm}$ soil depth. There is general agreement between the observed and simulated carbon levels for all of these variables. The greatest discrepancy is an overestimate of the large wood carbon and an underestimate for branch carbon. Model parameters for large wood, fine branch, fine root, and coarse root turnover times were adjusted to match the observed data. Turnover times for the surface litter (Oi) were not adjusted; however, the turnover time for the surface slow soil organic pool $(\mathrm{Oe} / \mathrm{Oa})$ and mixing rate of the Oe/Oa into the mineral soil were adjusted to match the observed data for the Oe/Oa layer. The turnover times of the soil slow pool and passive pools in Century were adjusted to get the observed total soil carbon levels (0$20 \mathrm{~cm}$ depth). Improvement in the model's ability to represent observed carbon levels for the different plant parts will be accomplished by further adjusting the turnover rates and including a Century schedule file that better reflects harvesting of the forests 80 to 100 years ago.
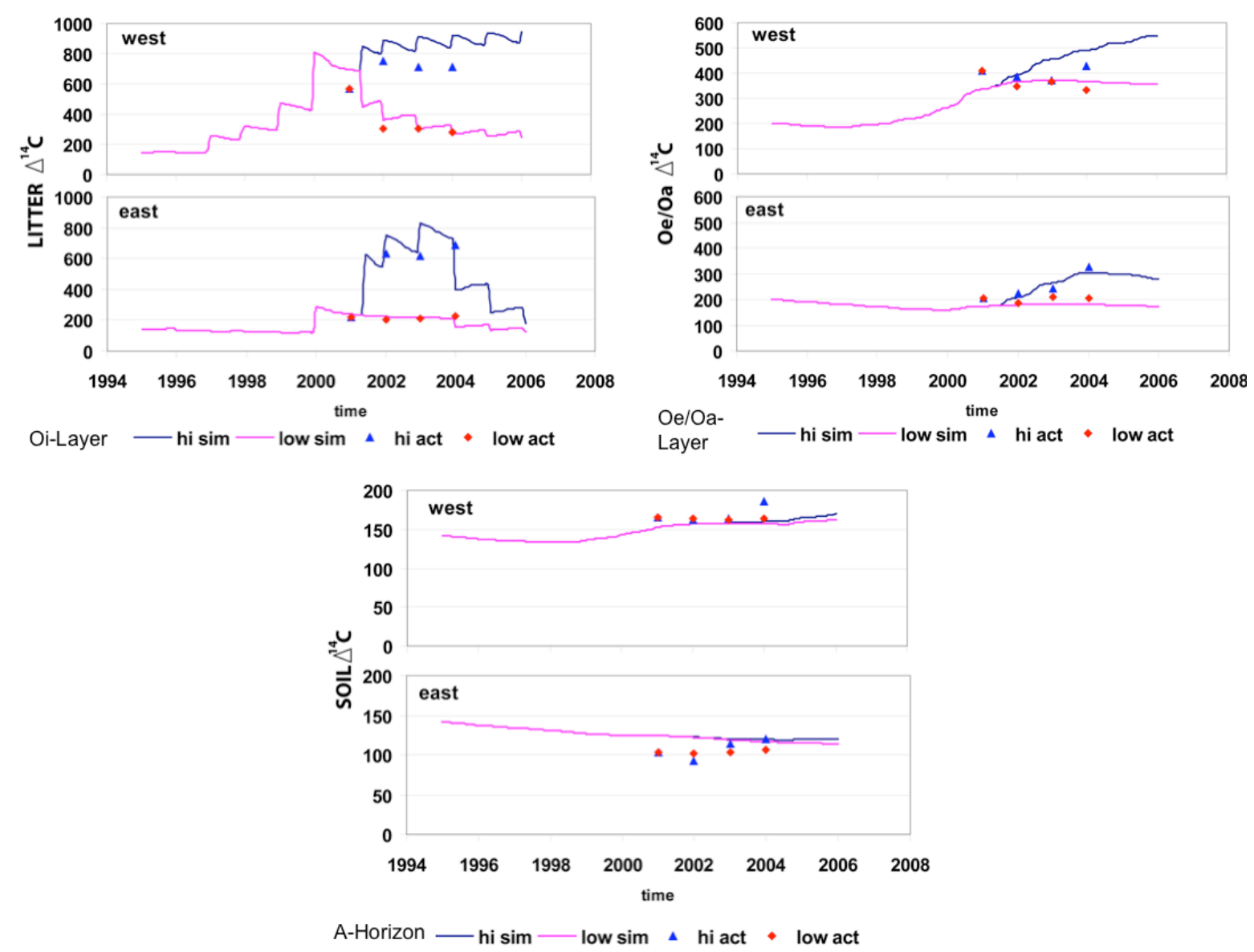

Figure 32 shows observed and simulated $\Delta^{14} \mathrm{C}$ content for the Oi-layer, Oe/Oa layer, and A-horizon $(0$ to $20 \mathrm{~cm}$ mineral soil) for east and west EBIS sites on the Oak Ridge Reservation.

Figure 32 indicates general agreement between the modified Daycent model simulations and the observed $\Delta^{14} \mathrm{C}$ for the Oi layer, Oe/Oa layer and the A horizon for both the enriched and near-background litter addition treatments. The overall comparison of the observed and simulated $\Delta^{14} \mathrm{C}$ of the Oi-layer is quite favorable. The model and data show that the $\Delta^{14} \mathrm{C}$ content of the Oi layer is higher for the west site compared to the east site, and that the near-background 
litter treatment has lower $\Delta^{14} \mathrm{C}$ compared to the enriched treatment. The overall fit of the model to the observed data from the east site is better compared to the west site, and there is a tendency for the model Oi $\Delta^{14} \mathrm{C}$ to be over estimated for the western high treatment site. The higher Oi $\Delta^{14} \mathrm{C}$ content of the west site compared to the east site reflects the higher atmospheric $\Delta^{14} \mathrm{C}$ content of the west site (Figure 31) which is well-represented by the model. A comparison of observed and simulated $\Delta^{14} \mathrm{C}$ of the Oe/Oa layer shows (as expected) that the model and data $\Delta^{14} \mathrm{C}$ in the high treatments increase following enriched litter additions. The model simulations for the west site capture the $\Delta^{14} \mathrm{C}$ increase of the Oe/Oa layer beginning in 1999 following the large atmospheric $\Delta^{14} \mathrm{C}$ exposures (see Figures 5 and 6). This contrasts with the simulated Oe/Oa $\Delta^{14} \mathrm{C}$ levels in the eastern site, which decrease until 2000 and then stabilize around 190 per mil for ambient plots with near-background litter additions. The model results compare well, but results from the east site are more consistent with fewer discrepancies. This pattern of better fit of the model to observed data from the east site is true for both the Oe/Oa layer and the Oi layer.

The A-Horizon data in Figure 32 contrast observed and simulated $\Delta^{14} \mathrm{C}$ bulk soil $(0-20$ $\mathrm{cm}$ soil depth) values. Simulated bulk soil $\Delta^{14} \mathrm{C}$ values prior to 1995 peaked in the $1970 \mathrm{~s}$, following the end of atmospheric testing for atomic bombs (data not shown), and then started to decrease. Model results for eastern locations show a continuing pattern of decreasing $\Delta^{14} \mathrm{C}$ values for both litter addition treatments. This contrasts with the western site results after 1995 where increases in soil $\Delta^{14} \mathrm{C}$ are simulated and perhaps weakly represented by the data. The observed data is consistent with model simulations showing higher bulk soil $\Delta^{14} \mathrm{C}$ values for the west side compared to the east side, and higher values of $\Delta^{14} \mathrm{C}$ by 2005 for the enriched litter treatment. The simulated pattern of higher values of soil $\Delta^{14} \mathrm{C}$ values for the enriched litter treatment is just starting to be shown in the observed data.

Future Daycent Model Improvements

The process of setting up the Daycent model to represent the observed NPP data from the Oak Ridge site and the dynamics of $\Delta^{14} \mathrm{C}$ in the different ecosystem pools revealed a number of issues with the model and uncertainty in some of the model parameters. The analysis showed that the mean plant production is well represented by the model; however, year-to-year variations in NPP are not well represented (data not shown in this report). This will be corrected by including a more accurate representation of the seasonal changes in allocation of carbon to growth of different plant parts and revising the way that stored plant carbohydrates are simulated in the model. Other issues for further consideration include: litter decay dynamics, incorporation of lessons-learned from the Roth $\mathrm{C}$ model, the role of the plant carbohydrate pool, revised estimates of soil organic matter turnover time, and the rate of mixing of the surface slow pool with the soil slow pool.

Literature Cited:

Hanson PJ, Wullschleger SD, Eds. (2003) North American Temperate Deciduous Forest Responses to Changing Precipitation Regimes. Springer, New York, 472 p. 


\section{Carbon-Cycle Modeling : Rothamsted Model (RothC) \\ W. Mac Post}

A widely used soil organic matter turnover model that is often used with ${ }^{14} \mathrm{C}$ data (RothC, Jenkinson 1990) was used to generate hypotheses about the distribution of ${ }^{14} \mathrm{C}$ among various decomposition pools prior to the experimental applications of labeled litter (Figure 33).

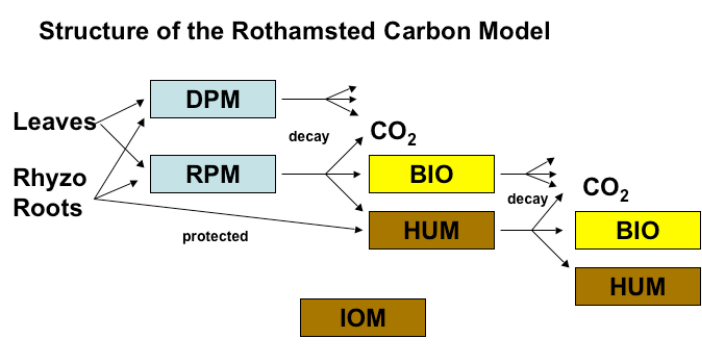

RPM : Resistant Plant Material DPM : Decomposable Plant Material HUM : Humified OM BIO : Microbial Biomass IOM : Inert OM
Recategorization of Rothamsted Compartments

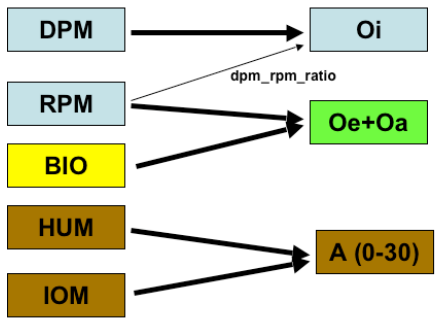

RPM : Resistant Plant Material DPM : Decomposable Plant Material HUM : Humified OM BIO : Microbial Biomass

Figure 33. Original structure of the RothC model (left) and the reassignment of the structural alignment for application to the measured EBIS carbon pools.

Simulations were again performed with the RothC model after 4 years of measurements to determine the adequacy of the model for describing the experimental data. Estimates of aboveground and belowground inputs combined with a reassignment of carbon pools in the RothC model to align with those measured in the experiment it was found that total carbon of each of the pools was estimated accurately by the model.

The amount of radiocarbon in the litter pools, however, was overestimated by $15 \%$ in year 1 and 30\% in years 2 and 3 (Figure 34). The discrepancy may be caused by a more complete separation of litter dynamics from mineral soil decomposition dynamics than is modeled. The RothC model, as well as all other process oriented soil $\mathrm{C}$ models were developed for agricultural or grassland ecosystem application. As a result, discrete litter layers are not well handled. For the EBIS experiment, a more detailed litter decomposition model is required.

Litter decomposition models that follow the change in amount and quality of annual additions of organic matter have been developed for forest ecosystems (Pastor and Post 1986). A general theoretical formulation of such models has been developed by Ågren and Bosatta (1996) called the Q-model or Quality model. A version of the Q-model is being developed to apply to the labeled litter cohorts of the EBIS experiment. Several challenges need to be overcome in applying the fairly theoretical model to the data at hand. First, there a description of how the cohorts change in quality through time needs to be developed. A litter decompositions model developed previously (LINKAGES, Pastor and Post 1986) uses the empirical description of litter quality change developed by Aber and Melillo (1982). This is approach links quality to lignin and nitrogen dynamics of the decomposing litter. Appropriate parameters for the Q-model partial differential equations can be estimated for the EBIS plots by comparison to the LINKAGES litter decomposition model which may be though of as a discrete approximation to the Q-model. Utilization of the Q-model will allow model components to be better aligned with pool structure 
and decomposition dynamics in a layered forest floor, allow inter-annual variation in decomposition, and account for preferential decomposition of more labile components of litter have greater influence on the model dynamics.

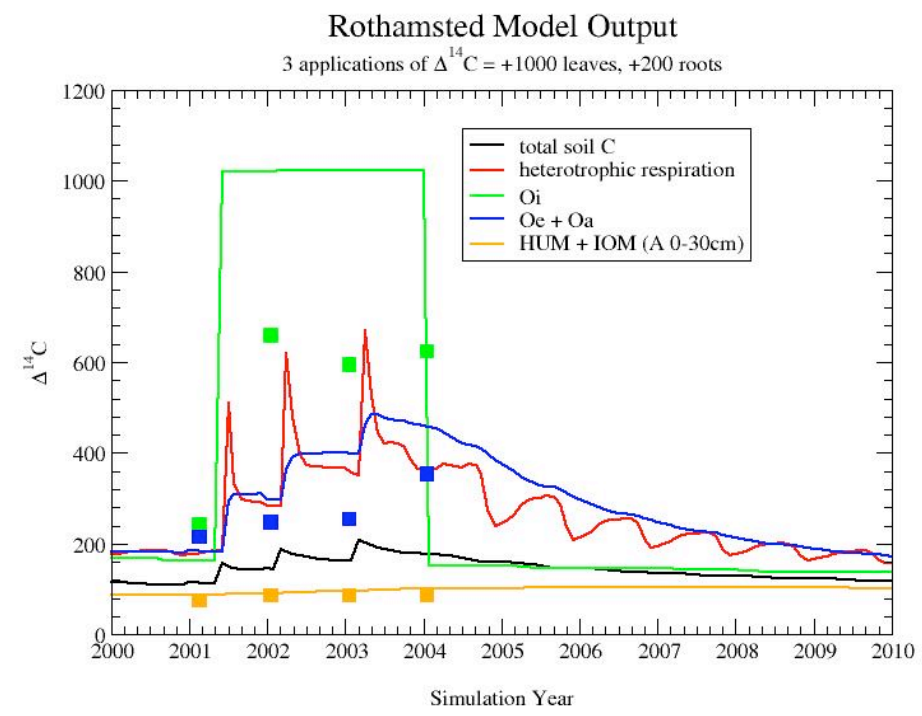

Figure 34. RothC simulations for the first three-years of the EBIS experiment (2000 to 2004) and a hypothetical progression for years beyond 2004.

References:

Ågren GI, Bosatta E (1996) Theoretical Ecosystem Ecology: Understanding Element Cycles. Cambridge University Press, Cambridge.

Pastor J, Post WM (1986) Influence of climate, soil moisture, and succession on forest carbon and nitrogen cycles. Biogeochemistry 2:3-27.

Jenkinson DS (1990) The turnover of organic carbon and nitrogen in soil. Philosophical Transactions of the Royal Society of London Series B - Biological Sciences, 329:361-368.

\section{Using EBIS Data to Evaluate the DyDOC Model (new collaboration)} Prof. Edward Tipping

Prof. Edward Tipping of the Center for Ecology and Hydrology, Lancaster in collaboration with Dr Paul Chamberlain have obtained independent research funding from The United Kingdom Natural Environment Research Council to fund a project titled "Modelling DOC production, transport and retention in forest soils, exploiting recent ${ }^{14} \mathrm{C}$ enrichment at Oak Ridge, USA." This project will utilize EBIS project data on DOC transport to conduct a rigorous evaluation of the efficacy of the DyDOC model. DyDOC is a process-based model that describes soil DOC pools, fluxes and concentrations, using sub-models for carbon metabolism, sorption to soil solids, and hydrology. The detailed EBIS field data will permit much more detailed and complete parameterization of the DyDOC model than is possible at other sites, and it is anticipated that DyDOC will be substantially advanced through interaction with the EBIS project. Their work will support all three of NERC's Science Strategic Priorities; the carbon cycling aspects are relevant to Earth's Life Support Systems and Climate Change, and the pollutant transfer properties of DOC to Sustainable Economies. 


\section{Soil $\mathrm{C}$ and ${ }^{14} \mathrm{C}$ Mass Balance}

Paul J. Hanson et al.

An evaluation of the carbon mass balance for our site using annual total $\mathrm{CO}_{2}$ efflux from the forest floor as an integrative reference point shows general agreement between inputs and outputs (Figure 33). While the approximate $100 \mathrm{gC} \mathrm{m}^{-2} \mathrm{y}^{-1}$ difference is non-trivial, such a difference could simply be accounted for by a larger estimate of annual root production and/or a change in the fractional contribution of autotrophic and heterotrophic respiration to total flux from the forest floor. Leaching losses from the root/soil complex are small and not responsible for the observed imbalances.

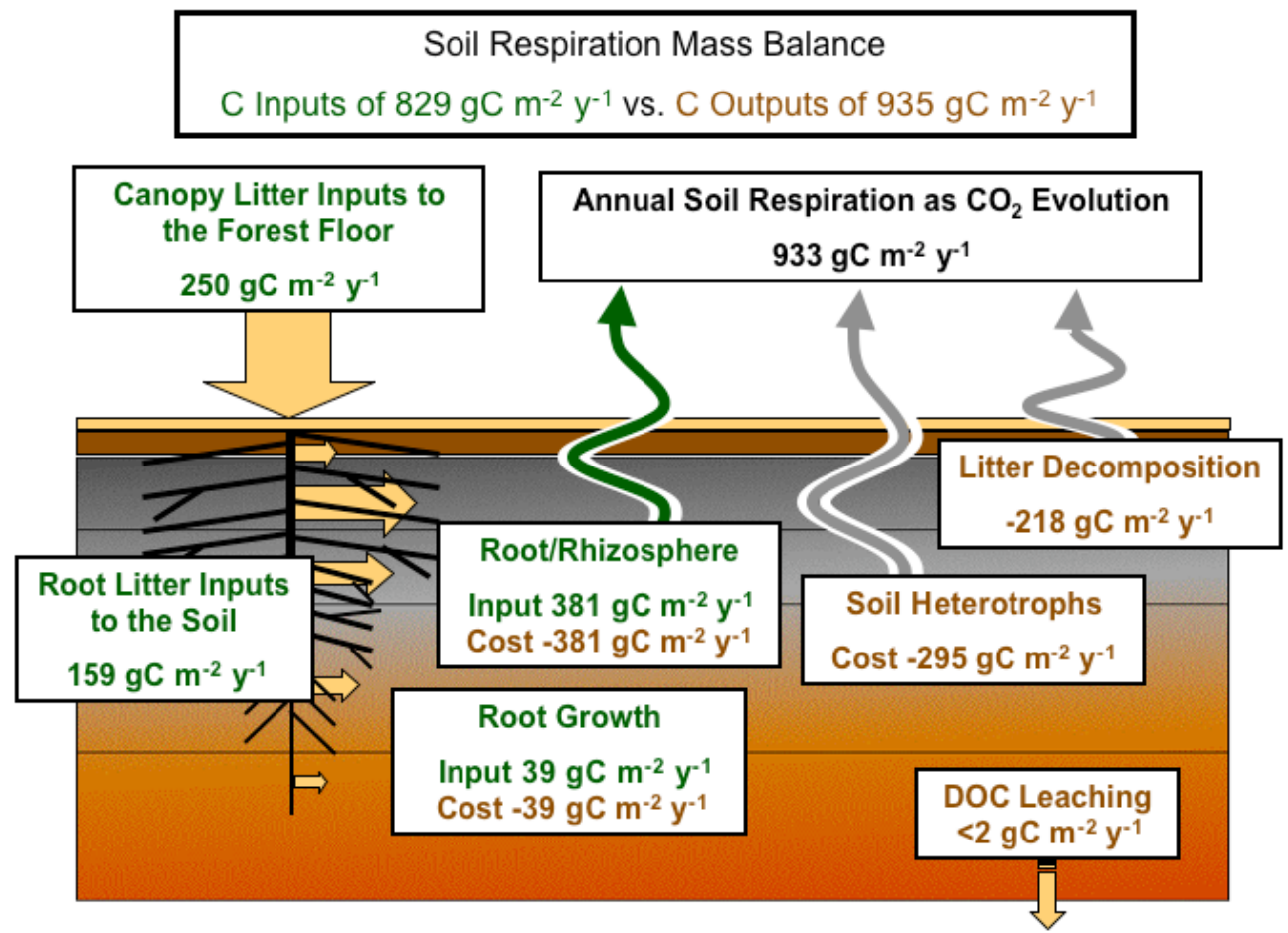

Figure 35. Measured and approximated values for carbon inputs and outputs associated with the annual soil C cycle on the Oak Ridge Reservation. Values in green and brown letters represent $\mathrm{C}$ inputs and outputs, respectively. Annual soil respiration is an integrated value for recent years on Walker Branch watershed.

The annual root production in Figure 35 was derived from root ingrowth core and minirhizotron observations for Walker Branch (Joslin and Wolfe 2003) and is considered highly variable. Because EBIS root-turnover observations demonstrated that the root standing crop is near equilibrium for the EBIS sites, it follows that root production should be nearly equivalent to heterotrophic losses from soils horizons occupied by roots minus the carbon inputs from canopy litter. Furthermore, because we have demonstrated that net DOC leaching inputs out of the rooted soil profile are small and that vertical movement of particulate carbon into the mineral soil is slow for these soils, we might anticipate agreement between the level of soil heterotrophic losses from the mineral soil and annual root litter inputs. That, however, does not appear be true (159 vs. $295 \mathrm{gC} \mathrm{m}^{-2} \mathrm{y}^{-1}$ ). The difference, $136 \mathrm{gC} \mathrm{m}^{-2} \mathrm{y}^{-1}$, might represent an underestimate of annual root litter production. Demonstrating higher rates of root production through detailed characterization of the new ${ }^{14} \mathrm{C}$ pulses in 2005 will go a long way towards resolving the $\mathrm{C}$ mass 
balance. A key objective of continued EBIS research activities through 2007 will be to resolve this issue.

The previous showed how we are using detailed process-based models to reconcile and understand measured and modeled ${ }^{14} \mathrm{C}$ flux patterns for the EBIS study sites, and showed that coarse resolution soil $\mathrm{C}$ cycling models needed spatial detail additions to capture the measured $14 \mathrm{C}$ patterns. Table 3 lists key process for which we have $\mathrm{C}$ and ${ }^{14} \mathrm{C}$ pool and/or flux data within the EBIS project and areas for which data are still lacking.

Table 3. Key soil carbon cycling process and the status of data collected for them in the first three years of the EBIS project.

\begin{tabular}{lll}
\hline Critical Process & Related C measurement & Related ${ }^{14} \mathrm{C}$ measurement \\
\hline Total $\mathrm{CO}_{2}$ Efflux & Flux chambers & Flux chambers \\
Canopy Litter inputs & Litter baskets \\
$\begin{array}{l}\text { Root litter production } \\
\text { Litter decomposition }\end{array}$ & $\begin{array}{l}\text { Subject to large error } \\
\text { Reconciled with historical mass } \\
\text { loss data }\end{array}$ & $\begin{array}{l}{ }^{14} \mathrm{C} \text { dilution } \\
\text { Incubation of isolated tissue and }{ }^{14} \mathrm{C} \\
\text { mixing calculations }\end{array}$ \\
$\begin{array}{l}\text { Mineral soil heterotrophic } \\
\text { respiration }\end{array}$ & $\begin{array}{l}\text { Incubation of isolated soil minus } \\
\text { roots }\end{array}$ & $\begin{array}{l}\text { Incubation of isolated tissue and }{ }^{14} \mathrm{C} \\
\text { mixing calculations }\end{array}$ \\
$\begin{array}{l}\text { Root respiration } \\
\text { DOC transport from Oi to Oe/Oa } \\
\text { horizons }\end{array}$ & $\begin{array}{l}\text { Subject to large error } \\
\text { DOC transport from Oe/Oa to A } \\
\text { horizon }\end{array}$ & Mesocosm study initiated \\
$\begin{array}{l}\text { DOC leaching from deep soils } \\
\text { Macrobiotic transport potential }\end{array}$ & Mesocosm study initiated & Mesocosm study initiated \\
& Lysimeter data and water flux & Mesocosm study initiated \\
\hline
\end{tabular}

Reference

Joslin JD, Wolfe MH (2003) Fine root growth response. In: Hanson PJ, Wullschleger SD, Eds, North American Temperate Deciduous Forest Responses to Changing Precipitation Regimes. Ecological Studies, Vol. 166, Springer, New York, pp. 274-302. 


\section{LIST OF PUBLICATIONS AND PRESENTATIONS}

\section{Completed Publications:}

Trumbore S, Gaudinski JB, Hanson PJ, Southon JR (2002) A whole-ecosystem carbon-14 label in a temperate forest. EOS 83:265,267-268.

Hanson PJ, Swanston CW, Garten CT Jr., Todd DE, Trumbore SE (2005) Reconciling Change in Oi-Horizon ${ }^{14} \mathrm{C}$ With Mass Loss for an Oak Forest. Soil Science Society of America Journal 69:1492-1502.

Swanston CW, Torn MS, Hanson PJ, Southon JR, Garten CT, Hanlon EM, Ganio L (2005) Initial characterization of processes of soil carbon stabilization using forest stand-level radiocarbon enrichment. Geoderma 128:52-62.

Cisneros Dozal LM (2005) Using a ${ }^{14} \mathrm{C}$ release to partition soil respiration sources in a southeastern hardwood forest. PhD thesis, University of California, Irvine.

Cisneros-Dozal LM, Trumbore SE, Hanson PJ (2006) Partitioning sources of soil-respired $\mathrm{CO}_{2}$ and their seasonal variation using a unique radiocarbon tracer. Global Change Biology 12:194-204.

Jardine PM, Mayes MA, Mulholland PJ, Hanson PJ, Tarver J, Luxmoore RJ, McCarthy JF, Wilson GV (2006) Vadose zone flow and transport of dissolved organic carbon at multiple scales in humid regions. Soil Science Society of America Journal (in press).

Trumbore, S (2006) Carbon Respired by Terrestrial Ecosystems: Recent Progress and Challenges. Global Change Biology 12:141-153.

Treseder KK, Torn MS, Masiello CA (2005/2006) An ecosystem-scale radiocarbon tracer to test use of litter carbon by ectomycorrhizal fungi. Soil Biology and Biochemistry (in press).

Garten CT Jr., Hanson PJ, Todd DE Jr., Lu BW, Brice DJ. Natural ${ }^{15} \mathrm{~N}$ and ${ }^{13} \mathrm{C}$ abundance as indicators of forest $\mathrm{N}$ status and soil $\mathrm{C}$ dynamics . IN (K. Lajtha, and R.H. Michener, eds.) Stable Isotopes in Ecology and Environmental Science. Blackwell Science, Oxford (in press).

\section{Completed manuscripts in review:}

Joslin JD, Gaudinski JB, Torn MS, Riley WJ, Hanson PJ Unearthing live fine root turnover times in a hardwood forest: the roles of root diameter, soil depth, and root branching order. New Phytologist.

Callaham MA Jr., González G, Hale C, Heneghan L, Lachnicht S, Zou X Policy and management responses to earthworm invasions. Biological Invasions.

Garten, C.T., Jr., D.J. Brice, and D.E. Todd, Jr. Short-term recovery of $\mathrm{NH}_{4}{ }^{-15} \mathrm{~N}$ applied to a temperate forest Inceptisol and Ultisol in east Tennessee, USA. Communications in Soil Science and Plant Analysis

\section{Manuscripts being prepared for submission in 2006:}

Cisneros Dozal, LM, Trumbore SE, Winston G, Hanson PJ. Importance of leaf litter in soil respiration. For submission to Journal of Geophysical Research-Biogeoscience.

Cisneros Dozal, LM, Trumbore SE, Xu X, Zheng S, Seasonally changing sources of carbon for root respiration. For submission to New Phytologist. 
Fröberg M, Jardine PM, Hanson PJ, Swanston C, Todd DE, Palmer JA Rapid vertical transport and estimated magnitude of DOC flux from fresh litter to deep mineral soils. For submission to Soil Science Society of America Journal.

Gaudinski JB, Torn MS, Riley WJ, Dawson TE, Joslin JD, Trumbore SE, Majdi H, Hanson PJ. Growth of new roots and leaves from stored carbon reserves in temperate forest ecosystems estimated with a numerical model and radiocarbon data. For submission to Ecological Applications.

Hanson PJ, Trumbore SE, Garten CT, Post WM, Fröberg M, Swanston CW Multi-year fate and transport of carbon through the organic horizons of a deciduous forest: facilitated observations with ${ }^{14} \mathrm{C}$-enriched litter cohorts. For submission to Soil Science Society of America Journal.

Riley WJ, Gaudinski JB, Torn MS, Swanston C, Hanson PJ. Root lifespan and growth in a forested ecosystem using a numerical model tested with locally released radiocarbon. For submission to Ecological Applications.

Jastrow JD, O'Brien SL, Swanston CW, Hanson PJ (2005/2006) Incorporation of a wholeecosystem radiocarbon label into unprotected and protected soil carbon pools. Soil Science Society of America Journal.

Swanston CW, Torn MS, Kleber M, and Hanson PJ. (2006) Determining primary soil carbon inputs, storage, and fluxes in the Enriched Background Isotope Study. For submission to Global Biogeochemical Cycles.

\section{Published abstracts:}

Cisneros-Dozal L, Trumbore S, Hanson P, \& Xu X (2002) Partitioning of Soil Respiration Sources Using ${ }^{14} \mathrm{C}$-Enriched Leaf Litter and Roots in a Temperate Forest, Oak Ridge, TN. San Francisco, California, 6-10 December 2002, Eos Trans. AGU, 83(47), Fall Meet. Suppl., Abstract B11C-0766, 2002.

Cisneros-Dozal LM, Trumbore S, Hanson PJ and Winston G (2004) Quantifying Leaf Litter Decomposition and the Response to Moisture Changes Using ${ }^{14} \mathrm{C}$. American Geophysical Union, Joint Assembly, 17-21 May 2004, Montreal, Québec, Canada. Paper number B42A-03, Abstract 903.

Cisneros-Dozal LM, Trumbore S and Zheng S (2004) The Source of C for Root/Rhizosphere Respiration Using ${ }^{14} \mathrm{C}$ Enriched Roots in a Temperate Forest. American Geophysical Union, Fall Meeting 13-17 December, 2004, San Francisco, CA, Abstract B23A-0945.

Hanson PJ, Trumbore S, Gaudinski J, Swanston C, Torn M, Jastrow J, Joslin JD, \& Jardine P (2002) Enriched background isotope study (EBIS): application of an ecosystem-scale ${ }^{14} \mathrm{C}$ tracer to soil-carbon-cycle studies. Annual meeting of the Soil Science Society of America, November 10-14, 2002, Indianapolis, Indiana. Annual Meetings Abstracts 2002, S07-hanson095634.

Hanson PJ, Trumbore SE, Swanston CW, et al. (2004) Distinct organic and mineral soil carbon cycles in an upland oak forest: evidence from multi-year ${ }^{14} \mathrm{C}$ enriched litter additions. Annual Meeting Abstracts Soil Science Society of America, October 31 to November 4, 2004, Seattle, Washington. S07-Hanson 6065

Hanson PJ, Trumbore SE, Swanston CW, Garten CT, Callaham MA, Jardine P, Post WM (2005) Multi-Year Dynamics of Upland-Oak Forest Organic Horizons: Observations Based on a Unique 14C-Tracer and a Mechanistic Model. Eos Trans. AGU, 86(52), Fall Meet. Suppl., Abstract B51E-08. 
Jastrow JD, O'Brien SL, Van Til BE, Matamala R, Swanston CW, Hanson PJ (2003)

Incorporation of a whole ecosystem radiocarbon label into unprotected and protected soil carbon pools, p. 47. In Book of Abstracts, Soil Ecology Society Ninth Biannual International Conference, Palm Springs, California. 11-14 May 2003.

Joslin JD, Gaudinski JB, Torn MS, Swanston C, Hanson PJ \& Todd DE (2003) Turnover of fine root carbon in a ${ }^{14} \mathrm{C}$-labeled forest ecosystem. In the 95th Annual Meeting of the American Society of Agronomy, Denver, CO, November 2-6, 2003. Agronomy Abstracts.

Todd DE, Tarver JA, Mehlhorn TL, Swanston C, Hanson PJ and Jardine PM (2003) Transport and sequestration of organic $\mathrm{C}$ in contrasting soils amended with $\mathrm{C}-14$ enriched leaf litter. In the 95th Annual Meeting of the American Society of Agronomy, Denver, CO, November 2-6, 2003. Agronomy Abstracts.

Torn MS (2005) Are Roots the Source of All Soil Organic Matter? Results From Isotopic Experiments in Temperate Forests EOS Trans. AGU, 86(52), Fall Meet. Suppl., Abstract B51E-04.

Treseder KK, Torn MS, Masiello CA (2003) Do ectomycorrhizal fungi use soil carbon? A field test with large-scale radiocarbon enrichment. Abstracts the Ecological Society of America 88th Annual Meeting, 3-8 August 2003, Savannah, Georgia, p. 337.

\section{Other presentations:}

Cisneros Dozal LM, Trumbore S, Hanson PJ, Xu X (2003) Quantifying Sources of Soil Respiration Using ${ }^{14} \mathrm{C}$-Enriched Leaf Litter and Roots in a Temperate Forest. National Science Foundation North American Carbon Program Joint PI Meeting (NACP '03), Arlington, Virginia, 12-14 May 2003.

Callaham MA Jr., Hanson PJ, Todd DE Jr. (2005) Tracing ${ }^{14} \mathrm{C}$ labeled leaf litter through oakhickory forest soils with native or introduced earthworms. Poster presentation at the Soil Ecology Society meetings, Argonne National Laboratory, Argonne, IL, May, 2005.

Gaudinski J, Riley W, Torn M, and Joslin J (2003) Using a Locally Released Radiocarbon Label to Constrain Fine RootStored Carbon Inputs to Roots and Refinement of Isotopically Derived Fine Root Lifespans Using A Locally Released Radiocarbon Label in Oak Ridge, TN. AGU Fall Meeting, 8-12 December, 2003, San Francisco, California.

Gaudinski JB, Torn M, Dawson T, Hooshang M \& Joslin D (2003) Quantifying fine root carbon inputs to soil: improving estimates of BNPP by combining results from radiocarbon and traditional methodologies. Conference on Fine Root Turnover Workshop in forested ecosystems. Swedish University of Agricultural Sciences, Uppsala, Sweden, September 8-10, 2003.

Hanson PJ, Trumbore S, Swanston C, Torn M, Jastrow J, Gaudinski J, Jardine P, Post WM, Cisneros-Dozal M, Garten CT Jr., Guilderson T, Joslin JD, Winston G, \& Callaham M (2003) Enriched Background Isotope Study (EBIS). DOE/BER Carbon Cycle Investigators Meeting, Boulder, Colorado. 16-17 October 2003.

Jastrow JD, O'Brien SL, Van Til BE, Matamala R, Swanston CW \& Hanson PJ (2003) Incorporation of a whole ecosystem radiocarbon label into unprotected and protected soil carbon pools. North American Carbon Program Joint PI Meeting 2003, Arlington, Virginia. 12-14 May 2003.

Jastrow JD, O’Brien SL, Van Til BE, Matamala R, Swanston CW \& Hanson PJ (2003) Incorporation of a whole ecosystem radiocarbon label into unprotected and protected soil 
carbon pools. DOE/BER Carbon Cycle Investigators Meeting, Boulder, Colorado. 16-17 October 2003.

Swanston C, Torn M, Hanson P, and Gaudinski J (2003) Radiocarbon flux into labile and stable soil organic matter pools in the Enriched Background Isotope Study (EBIS) 18th International Radiocarbon Conference, Wellington, New Zealand, from 1-5 of September 2003.

Swanston C, Torn M, Hanson P, and Gaudinski J (2003) Tracing radiocarbon from forest litter and roots into labile and stable carbon pools. International Conference on Mechanisms and Regulation of Organic Matter Stabilization in Soils, October, 5th - 8th, 2003, Munich, Germany.

Swanston CW, Torn MS, Jardine P, and Hanson PJ. (2005) Source and sink implications from elevated radiocarbon flux through three soil organic matter pools. 2nd International Conference on Mechanisms of Soil Organic Matter Stabilization, Asilomar, CA. 10-13 October, 2005.

Torn MS (2004) Soil Carbon Dynamics in Two Novel Cases: The Historic Russian Archives and the Tennessee Burp. Informal Seminar. University of Zurich, Switzerland.

Torn M, Gaudinski J, Treseder K, Westbrook J, Joslin D, Swanston C, Hanson P (2003) A Forest

${ }^{14} \mathrm{C}$ Pulse-Label Study of Root Turnover and Microbial Dynamics (EBIS). 18th International Radiocarbon Conference, Wellington, New Zealand, from 1-5 September 2003.

Torn MS, Treseder K, Westbrook J, Swanston C, and Hanson P (2003) A whole-forest ${ }^{14}$ C pulselabel study of microbial dynamics and soil organic matter (EBIS). International Conference on Mechanisms and Regulation of Organic Matter Stabilization in Soils, October, 5th - 8th, 2003, Munich, Germany.

\section{EBIS Education:}

Ph.D. Malu Cisneros-Dozal, University of California-Irvine 


\section{LIVERMORE WORKSHOP PARTICIPANTS}

\section{Project members:}

Mats Fröberg

Laura J. Hainsworth

Paul J. Hanson

Julie Jastrow

Markus Kleber

Christiane Kramer

Roser Matamala Paradeda

William J. Parton Jr.

Wilfred M. Post

Chris Swanston

Susan Trumbore
ESD-ORNL

LLNL-CAMS

ESD-ORNL

ANL

LBNL

UC-Irvine

ANL

Colorado State University

ESD-ORNL

LLNL-CAMS

UC-Irvine (gartenctjr@ornl.gov)

(ljhainsw@ehc.edu)

(hansonpj@ornl.gov)

(JDJastrow@ANL.gov)

(MKleber@lbl.gov)

(ckramer@uci.edu)

(matamala@anl.gov)

(billp@,nrel.colostate.edu)

(postwmiii@ornl.gov)

(swanston1@1lnl.gov)

(setrumbo@uci.edu)

\section{Unable to attend but provided discussion materials:}

Charles T. Garten, Jr

William Riley

Margaret Torn

Other interested persons:

Sarah O'Brien

Kelly Moran
ORNL

LBNL

LBNL

ANL

ANL (gartenctjr@ornl.gov)

(wjriley@1bl.gov)

(MSTorn@1bl.gov)

(sobrien@anl.gov)

(moran@uwm.edu) 